\title{
LA PRESTACIÓN FARMACÉUTICA A TRAVÉS DE ALGUNAS CUESTIONES RELACIONADAS CON LA APERTURA DE OFICINAS DE FARMACIA (A PROPÓSITO DE LA STSJ, CONTENCIOSO-ADMINISTRATIVO, MADRID 31 ENERO 2020)
}

\author{
Juan José Fernández Domínguez \\ jjferd@.unileon.es \\ Catedrático de Derecho del Trabajo y Seguridad Social \\ Universidad de León \\ Juan José García Vieitez \\ juan.garcia.vieitez@unileon.es \\ Catedrático de Farmacología \\ Universidad de León \\ Guillermo Domínguez Fernández \\ gdomif@estudiantes.unileon.es \\ R \& D Scientist. LSNE-León
}

Resumen: Una sentencia que aborda el módulo de población como factor determinante para la autorización de nuevas oficinas de farmacia sirve de oportunidad para, de su mano, revisitar el permanente debate entre la liberalización y la planificación en la ordenación farmacéutica. A tal fin se examina su solución por el Tribunal de Justicia de la Unión Europea, la opción española a partir de la heterogénea traslación de los factores dados por el número de habitantes y distancia entre farmacias desde la norma básica estatal hacia las distintas leyes autonómicas en la materia y, en fin, algunos de los elementos fundamentales de una copiosísima jurisprudencia al respecto.

Palabras clave: Apertura de oficinas de farmacia; Libertad de establecimiento; Planificación farmacéutica

Abstract: A sentence that deals with the population module as a determining factor for the authorization of new pharmacies serves to revisit the ongoing debate between liberalization and planning in pharmaceutical management. To this purpose, the study examines its solution by the Court of Justice of the European Union, the Spanish option 
based on the heterogeneous translation of the factors of number of inhabitants and distance between pharmacies from the State norm to the different regional laws on the matter and, finally, some of the fundamental elements of a very wide jurisprudence.

Keywords: Opening of pharmacy offices; Freedom of establishment; Pharmaceutical planning

I. Sobre el supuesto de hecho en presencia y su trascendencia - II. La planificación farmacéutica y los límites a la libertad de establecimiento en la jurisprudencia europea - III. El contexto legal: de la norma estatal básica a la heterogeneidad autonómica en la consideración de la población y distancias como elementos a ponderar en la autorización de nuevas oficinas de farmacia - IV. Aspectos principales de la jurisprudencia sobre la apertura de oficinas de farmacia. La solución al caso estudiado - V. Bibliografía

\section{Sobre el supuesto de hecho en presencia y su trascendencia}

La sentencia comentada solventa el recurso contencioso-administrativo interpuesto contra la decisión desestimatoria del recurso de alzada que había decidido la Viceconsejera de Humanización de la Asistencia Sanitaria de la Comunidad de Madrid el 23 de agosto de 2018, y había sido formulado por la parte aquí actora contra la Resolución de 13 de junio de 2018 de la Dirección General de Inspección y Ordenación de la mencionada Consejería, por la cual se hizo pública la relación provisional de solicitudes admitidas y excluidas en el procedimiento de autorización de apertura de nuevas oficinas de farmacia iniciado por Resolución de 5 de marzo de 2018.

Los distintos actos administrativos, y sus fechas respectivas, presentan en esta ocasión una importancia notable, pues la primera parte de la sentencia tendría un gran interés si el propósito del presente análisis se asentara en los asuntos procesales de enjundia que aborda, no en vano se suscitan hasta cuatro cuestiones de inadmisibilidad motivadas por el hecho de que, literalmente, el escrito de interposición de la demanda aparecía dirigido contra la Resolución de 28 de agosto, aunque en el suplico se instara la declaración de nulidad de la Resolución de 13 de junio de 2018.

Bajo un esquema que atiende a un mismo modelo de respuesta, el Tribunal Superior de Justicia relativiza la importancia de los óbices procesales. Comienza, siempre, reconociendo el punto de razón que asiste al Letrado de la Comunidad Autónoma ("desde un punto de vista formal llevaría razón...", "cierto es que...", "pese a ser cierto que..." o "no falta razón a la demandada..."), pero acaba rechazando que el error o irregularidad alcancen magnitud bastante para provocar a la inadmisibilidad. Argumenta al respecto que: 
1) Si bien es cierta la variación en el objeto del proceso entre el que figura en el escrito de interposición y el recogido en el suplico, y las alegaciones no se dirigen contra la relación provisional de solicitudes admitidas, sino contra la previsión de autorización en concreto, no cabrá obviar que la resolución impugnada efectivamente contenía un pronunciamiento respecto de la cuestión suscitada como objeto central de debate a resultas de la petición última formulada por la parte demandante, sin que, por ese motivo, quepa apreciar desviación procesal alguna.

2) A pesar de que la Resolución de 5 de marzo de 2018 incluía en su publicación la indicación expresa de no agotar la vía administrativa, el órgano judicial no aprecia la ausencia de falta de recurso de alzada, al interpretar -nuevamente pro actione-que no es aquella la Resolución impugnada, sino la de 23 de agosto de 2018, desestimatoria del recurso de alzada contra la Resolución de 13 de junio de 2018.

3) Aun cuando ni la Resolución de 5 de marzo, ni tampoco la de 13 de junio, concretan el número de farmacias cuya apertura se autoriza, ambas, al calor de las solicitudes admitidas y excluidas, contienen referencias explícitas a tal cuestión, y además constan las alegaciones que en las dos fueron formuladas al respecto. Por tal motivo, no cabe considerar que la impugnación de la Resolución de 28 de agosto suponga la reproducción de otra resolución previa, consentida y firme.

4) Por último, si lo recurrido fuera tan solo la decisión sobre las solicitudes admitidas y excluidas provisionalmente en el proceso de autorización, no podría caber duda de que la parte actora carecería de legitimación por no formar parte del mismo; sin embargo, y en la medida en que la Resolución de 13 de junio contiene una respuesta específica a las alegaciones de parte sobre aquella cuestión relativa a la procedencia de autorizar un número u otro de oficinas de farmacia, está proporcionando esa legitimación que ahora se cuestiona.

Solventando el obstáculo procesal, el Tribunal aborda el asunto de fondo, centrado sobre los habitantes requeridos para la creación de un número determinado de oficinas de farmacia por incremento de población. En concreto, la demandante discute la procedencia de la apertura de una tercera oficina a la luz de las peculiaridades que reúnen ciertos habitantes censados en la localidad, pues -según su parecer- habrían de restarse del cómputo del padrón todos los ingresados en las plazas para estancias de larga duración de las tres residencias existentes, no en vano ninguno de ellos, en principio, adquirirían medicamentos o productos farmacéuticos en las oficinas municipales, sino que lo harían en las farmacias (o depósito) de los respectivos centros donde se alojan.

Supuesto ciertamente original, el análisis de la solución adoptada en el caso concreto sirve en este comentario al doble propósito fundamental de recorrer la normativa autonómica sobre cómputo de la población y previsión de distancias a efectos de autorizar la apertura de nuevas oficinas de farmacia, así como repasar, de la mano de la jurisprudencia, algunos de los problemas más salientes que han acompañado a un asunto en el cual las cuestiones fundamentales no dejan de ser recurrentes (si bien la evolución legal ha conseguido eliminar alguna de ellas) y, sin embargo, los detalles varían de manera importante, para así proporcionar un paisaje rico en matices cuya 
solución a día de hoy no corresponde al Tribunal Supremo, sino a los Tribunales Superiores de Justicia.

De no menor interés resulta, después de la solución al caso concreto, y como un argumento que lo refuerza, el extenso e interesante excurso sobre el criterio de viabilidad económica de las oficinas de farmacia y la exigencia de un abastecimiento a la población seguro y de calidad como dos factores a cohonestar (en la medida de lo posible) a la hora de proceder a la autorización. A través de la invitación que contiene a reflexionar sobre la doctrina jurisdiccional europea, proporciona atalaya inmejorable para situar el viejo debate sobre la necesidad de autorización para la apertura de nuevas farmacias y la amplitud a tal excepción a la libertad de establecimiento.

\section{La planificación farmacéutica y los límites a la libertad de establecimiento en la jurisprudencia europea}

Cuando el órgano judicial afirma que a la hora de decidir - tanto él ahora, como antes la autoridad gubernativa correspondiente- "no han de regirse solo por los criterios de viabilidad económica (...), sino más bien [por] el prevalente de eliminar el riesgo de la falta de abastecimiento seguro y de calidad", toma parte de manera decidida en un debate que, si bien ya suscitado con anterioridad, ha venido ocupando un primer plano a lo largo del siglo: la liberalización o desregulación del mercado farmacéutico.

Teniendo siempre presentes los importantes intereses económicos que subyacen a la pretensión ${ }^{1}$, la cuestión pasa casi sin transición desde las discrepancias respecto a cuanto se considera más eficaz o supone un servicio al ciudadano en mejores condiciones de calidad y precio $^{2}$, hacía la decisión jurídica de reservar (o no) la

Sobre el volumen de negocio, y la decisión trascendente derivada de las variables propiedad y/o titularidad junto a la gestión de la actividad, baste comprobar los datos que al debate aportaron hace una década GONZÁLEZ ALONSO, I. y BARA BANDRÉS, M. P.: "Grandes cadenas de farmacias presentes en el entorno europeo", Farmacéuticos Comunitarios, Vol. 1, núm. 2, 2009, págs. 59-63. Respecto a los intereses de los diferentes actores en presencia, el esbozo de PÉREZ GÁLVEZ, J. F.: Farmacia y patrimonio: un estudio de la relación jurídica de servicio farmacéutico, Andújar (Ibarra de Arce), 1999, en particular págs. 28 y ss.

2 Entre otros análisis que detienen su atención en estos aspectos a la luz de reformas que los han convertido en guía última en diferentes países, sirvan la muestras de WAGNER, A. et alii: "Equity in the distribution of community pharmacies in England: impact of regulatory reform", Journal of Health Services Research \& Policy, Vol. 14, núm. 4, 2009, págs. 243248; GARATTINI, L.; VAN DE VOOREN, K. y CURICO, A.: "Will the reform of community pharmacies in Italy be of benefit to patients or the Italian National Service?", Drugs \& Therapy Perspectives, Vol. 28, núm. 11, 2012, págs. 23-26; KÄLVEMARKY SPORRONG, S. y NORDÉN-HÄGG, A.: "Trends in pharmacy staff's perception of patient safety in Swedish community pharmacies after re-regulation of conditions", Phamacy Practices, Vol. 12, núm. 4, 2014, págs. 1-5 o GOMES, M. et alii: "Dinâmica e concorrência regulada do mercado das farmacias em Portugal", Revista Portuguesa de Farmacoterapia, Vol. 9, núm. 2, 2017, págs. 213-221. El análisis de la evolución en nueve Estados en VOGLER, S.; HABIMANA, K. y ARTS, D.: "Does deregulation in community pharmacy 
propiedad de las farmacias en favor de farmacéuticos y/o condicionar la apertura de nuevas oficinas de farmacia a una ordenación predeterminada $\mathrm{y}$, por tanto, a unos requisitos de índole demográfico y/o geográfico.

Divididos prácticamente por la mitad los Estados europeos que optan por una u otra alternativa (sin perjuicio de una heterogénea mezcla que cabe seguir de la Tabla 1), ni la Comisión Europea, ni tampoco algunas importantes instituciones nacionales, han permanecido precisamente neutrales a la hora de abogar por una unificación de marcado signo liberalizador.

\section{Tabla 1}

\section{Principales características deferenciales de los sistemas farmacéuticos europeos}

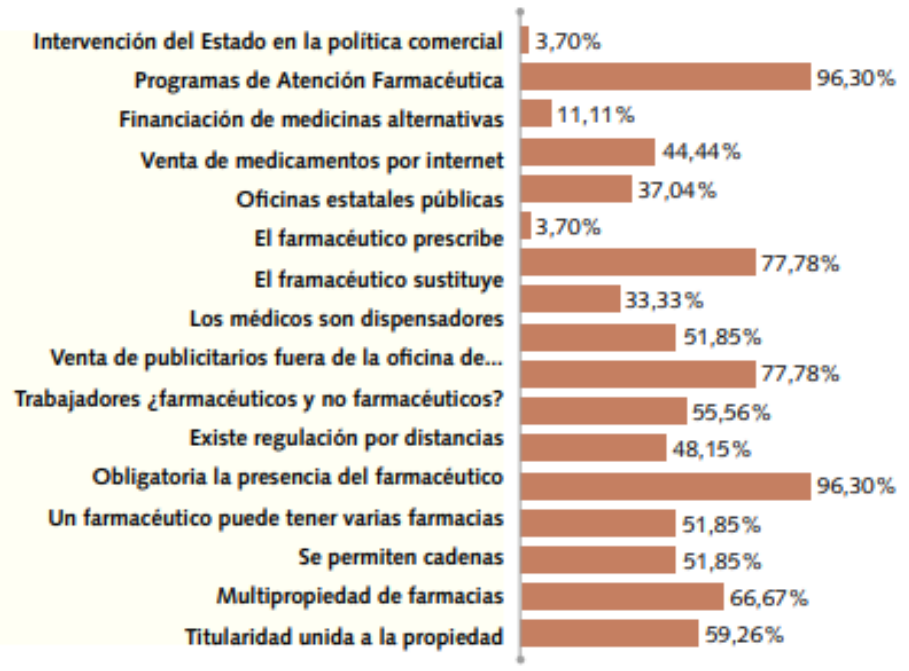

Fuente: GRANDA $(2001)^{3}$.

En este sentido, la Comisión Europea ha propugnado una política abiertamente liberalizadora en materia de oficina de farmacias, materializada en la incoación de hasta cuatros procedimientos contra Estados miembros (Alemania, Austria, España e Italia $)^{4}$. Estrategia "que ha desarrollado hasta 2008, cuando mostraba su intención de

impact accessibility of medicines, quality of pharmacy services and costs? Evidence from nine European countries”, Health Policy, Vol. 117, núm. 3, 2014, págs. 311-327.

3 GRANDA, E.: "Modelos de farmacia: comparativa europea. ¿Somos diferentes?", Farmacia Profesional, Vol. 25, núm. 2, 2011, pág. 16. Una visión comparada, anterior en el tiempo pero más exhaustiva, en GONZÁLEZ ALONSO, I. y BARA BANDRÉS, M. P.: "Modelos de farmacia en la Unión Europea. Análisis comparativo", Farmacia Profesional, Vol. 22, núm. 8, 2008, págs. 10-15.

4 En este sentido cabrá remitir a Comisión Europea, IP/06/858, Bruselas, 28 junio 2006; e IP/06/1352, Bruselas, 18 septiembre 2008. Con detalle, EZQUERRA HUERVA, A.: "El 
continuar los procedimientos por incumplimiento a través de la Dirección General de Mercado Interior y Servicios en distintos ámbitos del mercado interior, citando expresamente los relativos a la movilidad de los pacientes y el reembolso de los costes médicos, el establecimiento de farmacias, etc. Al mismo tiempo, la Comisión se ha propuesto perseguir las violaciones más groseras del art. 43 TEC, que consagra el derecho de establecimiento, y del art. 49 TCE, relativo a la libre prestación de servicios, en relación con los servicios de salud y lo que la Comisión denomina 'las discriminaciones patentes en el sector de las farmacias" $"$.

En España, y con ecos en una vieja reivindicación del Defensor del Pueblo al calor del principio 'pro apertura' en la autorización del establecimiento de nuevas farmacias $^{6}$, cabrá dar cuenta de la contundente toma de posición del Tribunal de Defensa de la Competencia ${ }^{7}$, la formulación en 2008 de una decisión prejudicial por el Juzgado de lo Contencioso-Administrativo de Granada cuestionando su compatibilidad con el art. 43 TCE (por avocar a "un sistema de limitación del número de farmacias desproporcionado, incluso contraproducente, respecto al objetivo del buen abastecimiento de medicamentos del territorio de que se trate") ${ }^{8}$ o la activa lucha mostrada por las asociaciones a favor de la libre apertura de oficinas con argumentos que han venido encontrando amplio eco social ${ }^{9}$.

No tuvieron el éxito pretendido ni la actuación a nivel supraestatal, ni tampoco las iniciativas nacionales tuvieron el éxito pretendido, cercenadas de raíz por un Tribunal de Justicia de la Unión Europea convertido en árbitro (legislador negativo ${ }^{10}$ ) que ha permitido conservar cuanto se ha considerado como "mercados intervenidos"11 (pues

modelo español de ordenación farmacéutica en el contexto comunitario europeo de libertad de establecimiento", Derecho y Salud, Vol. 16, 2008, págs. 20 y ss.

5 ORDÓÑEZ SOLÍS, D.: "La regulación española de las oficinas de farmacias en el contexto del mercado único a la luz de la jurisprudencia europea", Gaceta Jurídica de la Unión Europea y de la Competencia, núm. 10, 2009, pág. 19. Por extenso, HANCHER, L.: "The EU pharmaceuticals market: parameters and pathways", en AA.VV. (MOSSIALOS, E. et alii, Eds.): Health systems governance in Europe: The role of European Union Law and Policy, Cambridge (Cambridge University Press), 2010, págs. 635-682.

6 NICOLÁS ORTÍZ, C.: "Defensor del Pueblo: 'pro apertura' de farmacias", Farmacia Profesional, Vol. 8, núm. 9, 1994, págs. 5-9.

7 TRIBUNAL DE DEFENSA DE LA COMPETENCIA: La competencia en España: balance y nuevas perspectivas, Madrid (Tribunal de la Competencia), 1995, pág. 229-271.

8 Decisión prejudicial C-563/08, asunto Carlos Sáez Sánchez y Patricia Vargas Rueda c. Junta de Andalucía y Manuel Jalón Morente y otros, de 18 de diciembre de 2008 (DOUE 2009/C 69/37).

9 Un sucinto elenco de estos argumentos, y también de los contrarios, en PÉREZ GÁLVEZ, J. F.: "Libertad de establecimiento de farmacias en la Unión Europea", Revista de Derecho de la Pontificia Universidad Católica de Valparaíso, Vol. XXXV, 2010, $2^{\circ}$ semestre, págs. 367 y 368.

10 WASSERFALLEN, F.: "The judiciary as legislator? How the European Court of Justice shapes policy-making in European Union”, European Public Police, Vol. 17, núm. 8, 2010, págs. 1128-1146.

11 Elocuente la justificación al respecto de NIETO, A.: "La Ley alemana de Farmacia de 28 de agosto de 1960", Revista de Administración Pública, núm. 35, 1961, pág. 361. Sobre la exclusión de la Ley de Sociedades profesionales, precisamente como "impulso de las 
"adolecen de rigideces que les impiden adaptarse a las necesidades actuales"12) o, desde otra perspectiva, garantiza la autonomía de cada país a la hora de decidir un régimen de liberalización o de normas más o menos restrictivas para dar lugar así a esa elocuente "asimetría constitucional"13, que en el caso español admitirá diversidad de grados en función del ejercicio de competencias transferidas a las Comunidades Autónomas ${ }^{14}$.

Este apunte sobre el estado de la situación, surgido de una posición jurisprudencia firme, exige recordar cómo, en su momento, el mantenimiento de los modelos nacionales heterogéneos, incluidos los ejemplos más notorios de restricciones a la libertad de establecimiento en el ámbito farmacéutico ${ }^{15}$, encontró una posible justificación expresa en aquel pronunciamiento en el cual se venía a establecer que "en el Estado actual del Derecho Comunitario, en el que no se ha conseguido la armonización de las normas relativas a la comercialización interior de cada Estado miembro (...), el establecimiento de normas relativas a la dispensación propiamente dicha de los productos farmacéuticos sigue siendo competencia de cada uno de los Estados miembros, siempre que se respeten las disposiciones del presente Tratado y, en particular, las que se refieren a la libre circulación de las mercancías (...). La existencia de monopolio farmacéutico puede estar justificada por uno de los intereses generales mencionados en el artículo 36 del Tratado, entre los que figuran la protección de la salud y la vida de las personas. Además, al ser, en principio, indistintamente aplicable a los productos nacionales y a los importados, este monopolio también puede estar justificado por la protección de los consumidores que, conforme a la jurisprudencia de este Tribunal de Justicia, figuran entre las exigencias imperativas que pueden justificar una medida que puede obstaculizar el comercio intracomunitario"16.

autoridades sanitarias españolas y de los representantes profesionales de los farmacéuticos para frenar los requerimientos liberalizadores de la Comisión Europea", VILLALBA PÉREZ, F. L.: "Disposición adicional sexta. Oficinas de farmacia", en AA.VV. (GARCÍA PÉREZ, R. y ALBIEZ DOHRMANN, K. J., Dirs.): Comentarios a la Ley de Sociedades Profesionales. Régimen Fiscal y Corporativo, Cizur Menor (Aranzadi/Thomson), 2007, pág. 708.

12 PÉREZ GÁlVEZ, J. F.: "Libertad de establecimiento de farmacias en la Unión Europea", cit., pág. 365 .

13 SHARPF, F. W.: "The European social model”, Journal of Common Market Studies, Vol. 40, núm. 4, 2002, pág. 647.

14 Una perspectiva llena de contestaciones al quehacer de Tribunal de Justicia en BROOKS, E.: "Crossing borders: A critical review of the role of the European Court of Justice in EU health policy", Health Policy, Vol. 105, núm. 1, 2012, págs. 33-37.

15 En este sentido, GARCÍA ESCRIBANO MARTÍNEZ, M. S.: El derecho de establecimiento de las oficinas de farmacia en la Unión Europea, Tesis Doctoral, Universidad Complutense, 1997, en dialnet.unirioja.es/servlet/tesis?codigo=173761.

16 STJCE C-369/88, de 21 de marzo de 1991, asunto Delattre. Una valoración de su sentido por cuanto aquí interesa en MORALES ARIZA, S. M.: Ordenación farmacéutica española: situación actual y perspectivas de futuro, Tesis Doctoral, Universidad de Valencia, 2015, pág. 202 en https://core.ac.uk/reader/71056520 o SERRATO MARTÍNEZ, L.: Régimen jurídico-administrativo del medicamento, Tesis Doctoral, Universitat de Lleida, 2014, en https://repositori.udl.cat/handle/10459.1/64107. 
La cuestión viene a ser retornada dos décadas después, a través de cuatro sentencias del Tribunal de Justicia en las cuales cuanto se debate son precisamente los cimientos sobre los cuales se asienta el modelo español de ordenamiento farmacéutico.

Las dos primeras, de 2009, aun cuanto las posiciones de las partes sean netamente distintas, abordan y resuelven bajo argumentos prácticamente idénticos cuestiones relativas a la compatibilidad de la normativa nacional que reserva la propiedad y explotación de una oficina de farmacia a quienes ostentan la titulación de farmacéutico con cuanto recogía sobre la libertad de establecimiento el entonces art. 43 del Tratado Comunitario de la Unión Europea (TCE) $)^{17}$. En ellas, tras negar que el supuesto presente similitud con un pronunciamiento previo sobre la profesión de óptico y la titularidad de tales establecimientos (dando el carácter peculiar de los medicamentos y su mercado, así como el estado actual de Derecho Comunitario) ${ }^{18}$, sienta tres premisas que van a orientar el razonamiento posterior y justificarán el fallo ${ }^{19}$ :

- A partir de la jurisprudencia que las precedió, así como de cuanto disponen no solo la Directiva 2005/36/CE, de 7 de septiembre de 2005 (cuyo considerando vigésimo sexto no coordina las condiciones de acceso a las actividades de ámbito farmacéutico y su ejercicio, estableciendo que la distribución geográfica de las farmacias y el monopolio de dispensación de medicamentos sigue siendo competencia de los Estados), sino también - cabría añadir, aun cuando la sentencia lo ignora ${ }^{20}$ - la Directiva 2006/123/CE, de 13 de diciembre de 2006, relativa a los servicios de mercado interior [con la exclusión de su aplicación ex art. 2.2 f), justificada en el considerando vigésimo, en tanto "debe abarcar los servicios sanitarios y farmacéuticos prestados por profesionales de la salud a pacientes con objeto de evaluar, mantener, restaurar su estado de salud, cuando estas actividades están reservadas a profesiones reguladas en un Estado miembro"], resulta claro que la Unión Europea carece de normativa específica al respecto y que el parámetro de control único ha de venir dado por cuanto antes recogía el art. 43 TCE y ahora lo hace el art. 49 del Tratado de Funcionamiento de la Unión Europea (TFUE). De este modo, los Estados miembros ostentan la competencia para ordenar las oficinas de farmacia, pero lo han de hacer con respeto al Derecho Comunitario y, en especial, a las libertades de circulación, incluidas la de capitales y de establecimiento; por ello, será de recibo un margen de apreciación en favor de cada país, pero no cabrá establecer o mantener restricciones injustificadas.

17 STJCE C531/06, de 19 de mayo de 2009, asunto Comisión a Italia y C-171/02 y C-172/07, de 19 de mayo de 2009, asunto Apothekerkammer des Saarlands.

18 La referencia lo es a la STJCE C-140/03, de 21 de abril de 2005, asunto Comisión c. Grecia.

19 RAZQUIN LIZARRAGA, J. A.: "La reserva de la propiedad y la titularidad de las oficinas de farmacia a los farmacéuticos no es contraria al Derecho Comunitario Europeo", Actualidad Jurídica Aranzadi, núm. 777, 2009, BIB\777\2009.

20 GARCÍA DE PABLOS, J. F.: "Apertura de farmacias en España y libertad de establecimiento", Aranzadi Doctrinal, núm. 10, 2011, BIB\2010\3044. Muy crítico al respecto el planteamiento de BAETEN, R.: "Was the exclusion of healthcare from the Services Directive a pyrrhic victory? A proportionality test on regulation of health professions", OSE Paper Series, núm. 18, 2017. 
- En uso de esta competencia, la disparidad de regímenes entre los Estados miembros es evidente, pues en algunos de ellos la propiedad y la explotación han de coincidir en un farmacéutico autónomo, mientras otros aceptan que quienes no ostentan la condición de farmacéuticos autónomos puedan ser titulares de negocio, si bien habrán de encargar la gerencia a farmacéuticos contratados.

- Piedra axial en la concreción de este margen regulador conferido a los Estados, y de las diferentes opciones en presencia, es la doctrina asentada a cuyo tenor "la salud y la vida de las personas ocupan el primer puesto entre los bienes e intereses protegidos por el Tratado", pudiendo "el Estado miembro decidir qué nivel de protección de la salud pública pretende asegurar y de qué manera debe alcanzarse ese nivel"21.

A partir de estas consideraciones, la sentencia aborda la cuestión relativa a si la restricción evidente que supone la necesidad de que el titular y quien explota la oficina de farmacia sea un farmacéutico (sin discriminación por razón de nacionalidad) está suficientemente justificada "por razones imperiosas de interés general" (y la protección a la salud lo es, expresada en esta ocasión por un abastecimiento de medicamentos seguro y de calidad a la población ${ }^{22}$ ), siempre que sean adecuadas para garantizar la realización de la finalidad que persiguen y no vayan más allá de lo que es necesario para alcanzar dicho objetivo. De este modo, será la proporcionalidad en sentido amplio y estricto la llamada a solventar la cuestión en el caso concreto $^{23}$ :

1.- En cuanto al principio general de proporcionalidad hace, el Tribunal de Justicia sostiene que la exclusión de quienes no son farmacéuticos puede resultar adecuada para garantizar el propósito de asegurar un abastecimiento de medicamentos a la población seguro y de calidad, y por tanto la protección de la salud pública, ya que:

a) El consumo excesivo e incorrecto de medicamentos supone riesgos para la salud pública y para el equilibrio financiero de los sistemas de Seguridad Social, motivo por el cual los Estados miembros "pueden reservar la venta de medicamentos al por menor, en principio, exclusivamente a los farmacéuticos, debido a las garantías que estos deben presentar y a la información que deben ser capaces de proporcionar al consumidor"; siendo de recibo, por ende, la

21 Punto de partida en el discurso de VILLALBA PÉREZ, F.: "La protección de la salud como factor determinante de la libertad de establecimiento de la oficina de farmacia española y el Derecho Comunitario", Noticias de la Unión Europea, núm. 312, 2011, págs. 51-68.

22 Discutiendo que el mayor nivel de protección a la vida y la salud quede directa y necesariamente vinculado ("salto en el vacío del discurso") a la justificación de la normativa nacional en garantía de un abastecimiento seguro y de calidad, la crítica durísima de TAPIA HERMIDA, A.: "Las limitaciones a la apertura de nuevas farmacias", Revista de Trabajo y Seguridad Social (CEF), núm. 332, 2010, págs. 159-160 y 162.

23 Así, el planteamiento de BAETEN, R. y PALM, W.: "The compatibility of healthcare capacity planning polices with EU internal market rules", en AA.VV. (VAN DE GRODEN, J. et alii, Eds.): Healthcare and EU Law. Legal issues of services of general interest, La Haya (TMC Asser Press), 2011, págs. 389 y ss. 
exigencia de que los medicamentos sean distribuidos por farmacéuticos que acreditan una independencia profesional real ${ }^{24}$.

b) Teniendo en cuenta las tres categorías de potenciales titulares de una farmacia, el hecho de que lo sean farmacéuticos ofrece unas garantías de formación, experiencia profesional y responsabilidad de las que carecen quienes no tienen dicha condición ${ }^{25}$. En el supuesto de los farmacéuticos contratados por empresas del sector de productos farmacéuticos -y más aún en quienes en su condición de farmacéuticos están activos en el ámbito profesional como fabricantes o mayoristas- existe un riesgo que podría llevar a cuestionar su independencia ${ }^{26}$.

c) La coherencia de la normativa italiana que examina la primera de las sentencias no quiebra por las excepciones al principio de exclusión en caso de transmisión mortis causa, pues presentan carácter totalmente marginal y extraordinario, se justifican por la protección de los derechos e intereses patrimoniales legítimos de los familiares del farmacéutico fallecido y solo tienen efectos temporales. Tampoco por la posibilidad de que determinadas personas que no son farmacéuticos puedan explotar farmacias municipales, ya que no existe un riesgo de que los municipios, que son titulares de prerrogativa del poder público, se dejen guiar por un objetivo comercial particular y exploten las farmacias municipales en detrimento de las exigencias de la salud pública, pues los entes locales ostentan facultades de control sobre las sociedades y siguen siendo los titulares de tales farmacias.

2.- En cuanto hace a la proporcionalidad en sentido estricto, considera que en ambos supuestos "la normativa nacional resulta ser adecuada para garantizar la realización de su objetivo y no va más allá de lo necesario para alcanzarlo. En consecuencia, procede admitir que las restricciones que se derivan de dicha normativa pueden justificarse por ese objetivo" de garantizar un abastecimiento de medicamentos a la población seguro y de calidad.

24 Contestando abiertamente tal premisa, por "la desafortunada vinculación entre el régimen de titularidad de las farmacias y el coste público de la prestación farmacéutica", EZQUERRA HUERVA, A.: "Acerca del blindaje comunitario de la reserva de la propiedad de las oficinas de farmacia a favor de los farmacéuticos. Consideraciones al hilo de las sentencias del Tribunal de Justicia de las Comunidades Europeas de 19 de mayo de 2009 (asuntos acumulados C-171/07 y C-172/07, y asunto C-531/06)", Revista de Administración Pública, núm. 180, 2009, págs. 268-271.

25 Destacando que "su interés privado en la obtención de beneficios está mitigado por estos factores", CABEZAS LÓPEZ, M. D.; PIQUERAS GARCÍA, A. y GÓMEZ BETETA, J. E.: "El modelo mediterráneo de farmacia y la libertad de establecimiento en la Unión Europea”, Ars Pharmaceutica, Vol. 51, núm. 3, 2010, pág. 7.

26 Sobre estos riesgos, en un contexto más amplio, pero con cita precisamente del primero de los pronunciamientos, VILLALBA PÉREZ, F. L.: "La necesaria previsibilidad y estabilidad del ejercicio profesional del farmacéutico de oficina de farmacia", Revista Española de Derecho Administrativo, núm. 152, 2011, notas 4 y 36. 
El segundo de los pilares, situado en la planificación farmacéutica con restricciones a la apertura de nuevas oficinas a partir de criterios de población y distancia, encuentra el aval expreso un año después, para "cesar así la incertidumbre que pesaba sobre la compatibilidad de dicha normativa con las libertades económicas comunitarias" $" 27$.

El pronunciamiento, referido precisamente a la norma española (en concreto a la Ley 16/1997, de 25 de abril, de Regulación de los Servicios de las Oficinas de Farmacia -LRSOF-y al Decreto 72/2001, de 19 de julio, regulador de las oficinas de farmacias y botiquines del Principado de Asturias) ${ }^{28}$, supone una lectura "posibilista" del entonces art. $43 \mathrm{TCE}$ y actual art. $49 \mathrm{TFCE}^{29}$. Adjetivo, el entrecomillado, apropiado a la luz de las dos observaciones preliminares que se van a convertir en verdadera premisa de la ratio decidendi: de un lado, la competencia reconocida a los Estados para organizar sus servicios sanitarios, de los cuales forma parte las oficinas de farmacia, bajo el contexto reseñado de preeminencia de la salud y la vida y la decisión soberana en torno a los niveles de protección a conseguir y forma de hacerlo; de otro, e insistiendo en un rasgo tantas veces repetido, la inexistencia de una regulación europea sobre las condiciones para crear nuevas farmacias, los requisitos para su explotación o, más en concreto, que regule su ordenación territorial. Principio de subsidiariedad que signa de manera indeleble las vías de control, pues convierte al art. 49 TFUE en el patrón a utilizar a la hora de medir con tiento las excepciones a la libertad de establecimiento para no incurrir en restricciones injustificadas ${ }^{30}$.

Sobre el doble fundamento enunciado, no cabe duda que la norma española, con la exigencia de autorización condicionada a requisitos mínimos de población y distancias entre farmacias, introduce una restricción capaz de hacer menos atractivo para los farmacéuticos de otros Estados miembros el ejercicio de sus actividades en territorio español a través de un establecimiento. Ahora bien, la limitación puede estar justificada si supera el triple test dado por los principios de no discriminación-el cual no plantea mayores problemas en la ocasión que se juzga, al ser de aplicación con independencia de la nacionalidad-, necesidad -derivando la justificación de evidentes motivos de salud pública bajo la forma de garantía de un abastecimiento de medicamentos a la población seguro y de calidad $^{31}$ - y proporcionalidad ${ }^{32}$.

27 Perspectiva bajo la cual discurre el interesante y sucinto análisis de GARCÍA DE PABLOS, J. F.: "Apertura de farmacias y la normativa comunitaria", Actualidad Jurídica Aranzadi, núm. 801, 2010, BIB $2010 \backslash 1389$.

28 STJUE C-570/07 y C-571/07, de 1 de junio de 2010, asunto Blanco Pérez y Chao Gómez.

29 BAEYENS, A. y GOFFIN, T.: "Selected legislation and jurisprudence. European Court of Justice", European Journal of Health Law, Vol. 17, 2010, pág. 422.

30 PÉREZ GÁLVEZ, J. F.: "Libertad de establecimiento de farmacias en la Unión Europea", cit., 2010, p. 377.

31 Con mayor extensión sobre el test de necesidad en este caso concreto, CABEZAS LÓPEZ, M. D.; PIQUERAS GARCÍA, A. y GÓMEZ BETETA, J. E.: "El modelo mediterráneo de farmacia y la libertad de establecimiento en la Unión Europea", cit., p. 10.

32 Por extenso, RAZQUÍN LIZARRAGA, J. A.: "La ordenación territorial de las oficinas de farmacia en España y el Derecho de la Unión Europea (Sentencia del Tribunal de Justicia de 1 de junio de 2010, C-570/07 y C-571/07, Blanco Pérez y Chao C.)", Aranzadi Unión Europea, núm. 7, 2010, BIB $2010 \backslash 7412$. 
Este último se convierte, otra vez, en la clave del pronunciamiento final. El Tribunal lo considera cumplido por la normativa española con fundamento en tres argumentos:

- La planificación, incluida la autorización previa, puede resultar indispensable para colmar lagunas en el acceso a las prestaciones y para evitar una duplicidad de estructuras, de forma que se garantice una asistencia sanitaria adaptada a las necesidades de la población, que cubra la totalidad del territorio y tenga en cuenta las regiones geográficamente aisladas, o que de alguna otra manera se hallan en una situación de necesidad específica. Esta razón de ser es de aplicación plena a los prestadores de servicios sanitarios en el ámbito ahora objeto de atención.

La falta de regulación podría acarrear que los farmacéuticos se concentraran en las localidades consideradas más rentables y atractivas (aglomeraciones situadas en las zonas urbanas), y que otras localidades menos atractivas (zonas rurales, geográficamente aisladas o en una situación desventajosa) no dispusieran de un número suficiente de profesionales para garantizar una atención farmacéutica segura y de calidad $^{33}$. Ante el riesgo de escasez de farmacias en determinadas partes del territorio, el Tribunal admite la posibilidad de establecer un módulo de población mínimo que permita canalizar la implantación de farmacias hacia las partes del espacio nacional en las cuales el acceso a esta atención presente lagunas; al tiempo, impedir a los farmacéuticos establecerse en zonas donde ya existe un número suficiente de farmacias, e invitarles a instalarse en las que haya escasez. Por tanto, valora que el requisito es adecuado para distribuir las farmacias de manera equilibrada en el territorio nacional, en tanto permite garantizar a toda la población un acceso apropiado a la atención farmacéutica y, en consecuencia, aumentar la seguridad y la calidad del abastecimiento de medicamentos a la población ${ }^{34}$.

De otro lado, también sopesa que el requisito puede ser por sí solo insuficiente. Por ese motivo considera de recibo establecer requisitos adicionales destinados a impedir tal concentración, como es la exigencia de distancias mínimas entre las farmacias, pues permite evitar el riesgo y distribuir las farmacias de una manera más equilibrada en el interior de una zona geográfica determinada, así como aumenta la certidumbre de los pacientes de que dispondrán de una farmacia próxima y, por consiguiente, de un acceso fácil y rápido a una atención farmacéutica apropiada. En este sentido, el requisito de la distancia mínima es complementario de los módulos de población, pudiendo contribuir a la realización del objetivo que consiste en distribuir las farmacias de manera equilibrada en el territorio nacional y, de este modo, cubrir la garantía que fundamenta la decisión.

- No cabe afirmar que algunos farmacéuticos se vean privados del acceso a la actividad profesional mientras los establecidos en el mercado gozan de ventajas

33 Negando esta afirmación de partida, las razones que proporciona CERVERA SOTO, S.: "El modelo de atención farmacéutica en la legislación de Navarra", Derecho y Salud, Vol. 9 , núm. 1, 2001, págs. 1-8.

34 La discusión de esta premisa en LLUCH, M. y KANAVOS, P.: "Impact of regulation of community pharmacies on efficiency, access and equity. Evidence from UK and Spain", Health Policy, Vol. 110, núm. 2-3, 2010, págs. 245-254. 
desproporcionadas, por cuanto: de un lado, el criterio a ponderar son los imperativos de protección de la salud pública, y la importancia de los objetivos perseguidos en este ámbito puede justificar restricciones que tengan consecuencias negativas, incluso considerables, para algunos operadores; de otro, las autoridades competentes en este supuesto organizan al menos una vez al año un procedimiento para conceder autorizaciones de establecimiento de nuevas farmacias en función de la evolución demográfica; y, finalmente, la normativa nacional privilegia a los farmacéuticos que todavía no han obtenido una autorización de instalación para asegurar el acceso a más farmacéuticos al ejercicio profesional independiente, pues no será valorada la experiencia profesional como ejercicio de farmacéutico titular o cotitular en una oficina de farmacia, ni cualquier otra clase de méritos, cuando una u otros hubieran servido con anterioridad para obtener una autorización de instalación, dándose prioridad a los farmacéuticos que no hayan sido titulares de oficinas de farmacia ${ }^{35}$.

- La aplicación uniforme de las reglas generales de módulos de población y distancia mínima podría no garantizar una adecuada atención farmacéutica en zonas que tienen ciertas particularidades demográficas. Pero la normativa nacional prevé medidas de ajuste para atenuar los riesgos derivados de una aplicación estricta de la norma básica en cuanto al número de habitantes, pues las Comunidades Autónomas están facultadas para establecer módulos de población inferiores para las zonas rurales, turísticas, de montaña o aquellas en las que, en función de sus características geográficas, demográficas o sanitarias, no fuere posible la atención farmacéutica aplicando los criterios generales, de modo que las farmacias situadas en tales zonas particulares sean más accesibles para el segmento de la población que las rodean. Además, la dificultad derivada de la aplicación estricta de la distancia mínima entre farmacias puede atenuarse con la eventual reducción de esa regla general prevista en la normativa española, la cual incluso estaría en disposición de ser interpretada con carácter obligatorio siempre y cuando la aplicación estricta de la norma general consiga impedir que se garantice un acceso apropiado a la atención farmacéutica en determinadas zonas geográficas de gran concentración demográfica; cuestión a ponderar, a la vista de las circunstancias, por el órgano jurisdiccional al que corresponda.

- También, y en fin, supera el requisito de proporcionalidad en sentido estricto, pues a la vista del margen de apreciación de los Estados miembros en materia de protección de la salud pública, cualquiera de ellos puede considerar que el "sistema de mínimos" no permite lograr -con la misma eficacia que el sistema actual- el objetivo de garantizar el abastecimiento seguro y de calidad de medicamentos en las zonas poco atractivas ${ }^{36}$. Por tal motivo, legítimamente puede aspirar a organizar el sistema de distribución territorial a escala regional confiriendo a las diferentes

35 Por extenso, VILLABA PÉREZ, F. L.: La profesión farmacéutica, Madrid (Marcial Pons), 1996, en particular págs. 38 y ss.

36 Esta tensión entre los principios de una política social y cuanto pudiera derivar de esas exigencias mismas a partir de las cuales debería quedar todo sometido a la libre competencia en MOSSIALOS, E. y LEAR, J.: "Balancing economic freedom against social policy principles: EC Competition Law and national health systems", Health Policy, Vol. 106, núm. 2, 2012, págs. 127-137. 
Comunidades Autónomas (en este caso) la responsabilidad de organizar la distribución de las farmacias entre las zonas geográficas de sus respectivos territorios. La situación en las diferentes regiones puede ser considerablemente diferente respecto del establecimiento de los farmacéuticos, pues en algunas puede que no se haya alcanzado el número mínimo necesario de farmacias y, en cambio, en otras sí, estando todo su territorio disponible para el libre establecimiento, incluso las zonas más atractivas. Esta situación podría perjudicar el objetivo nacional de canalizar a los farmacéuticos hacia las zonas desprovistas de farmacias sin importar la región de que se trate; por tanto, no cabe considerar que la normativa española vaya más allá de lo necesario para lograr el objetivo perseguido.

Ecos evidentes, o continuidad en la doctrina, se encuentra en la última de las sentencias del TJUE, dedicada a la apertura de oficinas de farmacia sometida a autorización previa ${ }^{37}$. Sosteniendo, bajo los argumentos conocidos, que este sistema de prestación de asistencia se puede justificar por resultar indispensable para colmar posibles lagunas en el acceso a las prestaciones sanitarias, así como para evitar una duplicidad de estructuras, reitera la concesión a los Estados de un margen de aplicación a la hora de decidir el nivel de salud pública que pretenden alcanzar y la manera de hacerlo. Sin embargo, y en la medida en que esta opción por la autorización puede privar de eficacia a las disposiciones del Derecho de la Unión, y en particular a las de la libertad de establecimiento, recuerda que se trata de una excepción que "debe basarse en criterios objetivos, no discriminatorios y conocidos de antemano, que garanticen su adecuación para establecer suficientemente los límites del ejercicio de la facultad de apreciación por las autoridades nacionales".

En el caso de la normativa austriaca sometida a examen, la concesión de una licencia de apertura aparece supeditada a su "necesidad", que se presumirá existente salvo de concurrir las circunstancias que la propia ley contempla, relativas al número de prestadores sanitarios existentes en la zona, la distancia entre la farmacia cuya apertura se solicita y la más próxima y el número de personas a las cuales se debe abastecer de medicamentos ${ }^{38}$.

La aplicación uniforme de los requisitos de densidad demográfica, sin posibilidad de excepciones - al contrario de lo que ocurría en el supuesto de la normativa española antes analizado-, podría suponer que en determinadas zonas rurales cuya población está normalmente dispersa y es menos numerosa, algunos habitantes afectados se encontraran más allá de la distancia razonable de una farmacia y se vieran así privados de un acceso adecuado a la prestación. Nota que -según destaca de manera específicaresulta relevante en particular en lo que respecta a las personas con movilidad reducida. Dictamina a la postre, y a la luz de las libertades fundamentales, que el art. 49 TFUE se opone a la norma de un Estado miembro que establezca como criterio esencial, a efectos de comprobar la existencia de necesidad para la apertura de una nueva farmacia, un límite fijo de "personas a las que se debe continuar abasteciendo",

37 STJUE C-367/12, de 13 de febrero de 2014, asunto Sokoll-Seebacher.

38 Sobre estos parámetros objetivos, con el detalle debido para comprender el sentido último del pronunciamiento, MALENOVSKY, J.: "Apertura de nuevas farmacias (TJ Sala Cuarta, S 13 febrero 2014)”, La Ley Unión Europea, núm. 13, 2014, pp. 50 y 51. 
en la medida en que las autoridades nacionales competentes no puedan establecer excepciones a este límite para tener en cuenta particularidades locales ${ }^{39}$.

Doctrina que, no obstante, exigió una aclaración en auto posterior para sentar que, al hacer referencia a las regiones rurales o aisladas y a las personas de movilidad reducida, el Tribunal de Justicia no pretendía limitar el alcance de su apreciación sobre la congruencia de la legislación nacional controvertida en el litigio principal a este tipo de regiones o a esta categoría de personas, sino que se trataba de un mero ejemplo ampliable a otros capaces de provocar el mismo efecto ${ }^{40}$.

\section{EI contexto legal: de la norma estatal básica a la heterogeneidad autonómica en la consideración de la población y distancias como elementos a ponderar en la autorización de nuevas oficinas de farmacia}

Aun cuando la actividad farmacéutica siempre estuvo sometida a controles, la instalación de oficinas de farmacia a lo largo de la historia había venido siendo una decisión totalmente liberalizada, con un pasado próximo en el cual su apertura solo quedaba sujeta a los condicionantes recogidos en las Reales Ordenanzas de 1860. La extensión progresiva de prestaciones sanitarias y sociales hizo que el Decreto de 24 de enero de 1941 introdujera una regulación fuertemente restrictiva de tal régimen ${ }^{41}$, en decisión refrendada para proporcionarle nivel normativo adecuado por la Ley de Bases de Sanidad Nacional de 25 noviembre de 1944. La distancia entre farmacias pasaría a ser desde entonces -en particular a partir del Decreto de 31 de mayo de 1957- condicionante fundamental de la autorización, convertida en título jurídico que legitima a los farmacéuticos para el establecimiento de farmacias y cuyo objetivo radica en controlar, ordenar, orientar y planificar sobre el territorio la apertura y las modificaciones de estos establecimientos ${ }^{42}$.

A ese requisito de separación en metros unió el RD 909/1978, de 14 de abril, el módulo poblacional (art. 3) 43 , para alumbrar el modelo "moderno" de ordenación farmacéutica, que perdura bajo sus planteamientos hasta bien entrada la década de los

39 GARCÍA MONTOYA, L.: "Límites nacionales a la apertura de nueva farmacia vs. libertad de establecimiento del art. 49 TFUE", CESCO. Notas jurisprudenciales, 7 de abril de 2014. ATJUE C-634/15, de 30 de junio de 2016, asunto Sokoll-Seebacher y Nardehirn.

41 Sobre la limitación que recogiera la Orden de 28 de septiembre de 1934, pero que nunca fue de aplicación, LÓPEZ SANTIAGO, A.: "Apertura de oficinas de farmacia. Análisis de situación”, Farmacia Profesional, Vol. 15, núm. 9, 2001, pág. 29.

42 MARTÍN RETORTILLO, S.: "Acción administrativa sanitaria: la autorización para la apertura de farmacias", Revista de Administración Pública, núm. 24, 1957, en especial págs. 154 y 155.

43 GONZÁLEZ PÉREZ, J.: Nueva ordenación de las oficinas de farmacia, Madrid (BOE), 1978, o el muy sucinto pero sugerente ensayo de ZÚÑ̃IGA LÓPEZ, J. M.: "La apertura de las oficinas de farmacia al amparo de los arts. 3.1 B) del Real Decreto 909/1978, de 14 de abril, y 3.1 de la Orden Ministerial de 21 de noviembre de 1979”, La Ley, T. I, 1997, págs. 1819-1822. 
90, con la reforma acaecida en los años 1996 y $1997^{44}$, en los cuales se produjo sustitución parcial ${ }^{45}$. Larga vida e influencia que no impidió una doble crítica:

De un lado, se afirma que "constituyó una bomba de relojería a medio plazo que fue convenientemente, recebada por las órdenes ministeriales de desarrollo, al remarcar estas aún más el carácter pseudofuncionarial de las concesiones, bonificándose hasta extremos inconcebibles el ejercicio natural de la profesión, y complicándose las normas de mediciones de distancia para 'bunkerizar' las oficinas de farmacia sitas en núcleos importantes de población. Por ello, la mayoría de las solicitudes de oficinas farmacia terminan siendo objeto de recursos judiciales. Además, la no percepción de cantidad alguna por parte de los Colegios por la tramitación de los expedientes favoreció la práctica de solicitudes múltiples, por si en alguna había suerte, aunque estuviesen escasamente fundadas. Esto ha generado el colapso de los registros de Comunidades y Colegios" ${ }^{\prime \prime 6}$.

De otra, y después de aprobada la Constitución, se cuestiona abiertamente la compatibilidad de las limitaciones al libre establecimiento de oficinas de farmacia con cuanto contemplan, sobre todo, los art. 14, 35.1, 36 y $38 \mathrm{CE}^{47}$. Labor previa a hacer lo propio con el ordenamiento europeo en los términos antes expuestos, el Tribunal Supremo primero ${ }^{48}$, y el Tribunal Constitucional más tarde ${ }^{49}$, legitimaron el sistema y mantuvieron la norma hasta que el desarrollo del Estado de las Autonomías convirtió a las Administraciones territoriales en verdaderas protagonistas de la ordenación farmacéutica, entendida en el sentido que tempranamente le otorgó el máximo intérprete de la Norma Fundamental ${ }^{50}$.

44 La perspectiva en GONZÁLEZ FERNÁNDEZ, F. J.: "Las limitaciones a la libertad de apertura de nuevas oficinas de farmacia tras la reforma de la ordenación farmacéutica", en AA.VV. (SOSA WAGNER, F., Coord.): El Derecho Administrativo en el umbral del siglo XXI. Homenaje al Profesor Dr. D. Ramón Martín Mateo, Valencia (Tirant lo Blanch), 2000, pág. 1542. Por extenso, MUELAS TIRADO, J.: Régimen jurídico de apertura y actividad de las oficinas de farmacia, Tesis Doctoral, Universidad de Valencia, 2002, págs. 16 y ss., en dialnet.unirioja.es/servlet/tesis? codigo $=21867$.

45 Este apunte de continuidad en VIDAL CASERO, M. C.: "La apertura de oficinas de farmacia y la aplicabilidad del Real Decreto 909/1978, artículo 3.1”, La Ley, T. 2, 1996, págs. 1604.1607.

46 LOPEZ SANTIAGO, A.: "Apertura de oficinas de farmacia. Análisis de situación”, cit., pág. 29

47 Probablemente los mayores y mejores argumentos, y superior constancia, sobre esta incompatibilidad con el principio de igualdad, el derecho al trabajo y la libre elección de profesión y oficio, el derecho al ejercicio de las profesiones tituladas y el derecho a la libertad de empresa en RIVERO YSERN, J. L.: Libertad de establecimiento de oficinas de farmacia, Madrid (Trivium) 1992, págs. 36 y 49-56.

48 STS 10 mayo 1983 (s/rec.). En la doctrina, comentándola, GONZÁLEZ PÉREZ, J.: "La constitucionalidad de la legislación sobre establecimiento de farmacias (Sentencia de 10 de mayo de 1983)", Revista Española de Derecho Administrativo, núm. 39, 1983, págs. 597 y 598.

49 STC 83/1984, de 24 de julio.

50 STC 32/1983, de 28 de abril, cuando reza de manera concluyente que "la competencia comunitaria de ordenación farmacéutica (...) ha de entenderse referida a los establecimientos de venta al público de productos farmacéuticos”. En la doctrina, por todos, 
De este modo, y ubicada la ordenación de las farmacias dentro de la materia sanitaria -y no Seguridad Social, como hubiera sido también factible-, al Estado corresponde ordenar sus bases (art. 149.1.16 CE) y a las Comunidades Autónomas proceder a su desarrollo legal en uso de las competencias que le confiere el art. 149.1.21 $\mathrm{CE}^{51}$.

Convertidas la Ley General de Sanidad de 1986 (art. 103.3) y la Ley del Medicamento de 1990 (art. 88) en las normas que configuraron las primeras "bases de sanidad"52, fue preciso esperar al Real Decreto Ley $11 / 1996$, de 17 de junio ${ }^{53}$, y a la vigente Ley 16/1997, de 25 de abril, de Regulación de Servicios de Oficinas de Farmacia (LRSOF) para disponer de un modelo ajustado plenamente a las pautas constitucionales.

A partir de esta norma nacional cabrá comprobar cómo el Estado, "lejos de aportar una normativa básica en cuanto hace a la regulación del servicio farmacéutico a la población, se limita a las oficinas de farmacia, y su contenido básico común es más reducido, ya que a todos los contenidos del Decreto Ley [que la antecedió] le fue suprimido su carácter básico, con lo cual estamos ante una Ley que se dedica a establecer una serie de principios generales que dejan en manos de las Comunidades Autónomas prácticamente la entera regulación de la ordenación farmacéutica" ${ }^{94}$. Bien cabría sostener, por ende, que "el derecho directamente aplicable al procedimiento administrativo de autorización de apertura de oficinas de farmacia es autonómico"; a sus resultas, que "cada realidad territorial recuenta o cuenta los módulos poblacionales [y las distancias] teniendo en cuenta diferentes circunstancias" 55 , como producto de

MARTÍN MATEO, R.: “Ordenación farmacéutica, medicamentos y productos sanitarios", en AA.VV.: Jornadas Técnicas de Sanidad y Seguridad Social en el Estado de las Autonomias, Barcelona (Instituto d'Estudis de la Salud/Generalitat de Catalunya), 1984, pág. 127.

51 Por extenso sobre un asunto que en su momento no fue nada pacífico, los interesantes puntos de vista, por ejemplo, de CUETO PÉREZ, M.: Ordenación farmacéutica: regulación estatal y autonómica, Madrid (Marcial Pons), 1998, págs. 23 y ss.; BASSOLS COMA, M.: "Competencias transferidas a las Comunidades Autónomas en materia de Derecho Sanitario y Farmacéutico", en AA.VV.: Derecho Farmacéutico de las Comunidades Autónomas, Madrid (Consejo General de Colegios Oficiales de Farmacéuticos), 1987, págs. 61 y ss. o VILLALBA PÉREZ, F. L.: La profesión farmacéutica, cit., págs. 235 y ss.

52 Con detalle CUETO PÉREZ, M.: "Ordenación farmacéutica: competencias y funciones de las Comunidades Autónomas", Revista Española de Administración Local y Autonómica, núm. 276, 1998, en especial págs. 93-98, o, con un tenor más crítico, MARTÍN MATEO, R.: "La ordenación de las oficinas de farmacia", Derecho y Salud, Vol. 3, núm. 2, 1995, págs. 153 y ss.

53 GONZÁlEZ PÉREZ, J. y GONZÁLEZ SALINAS, E.: La reforma de la ordenación farmacéutica (Decreto-Ley 11/1996, y legislación de las Comunidades Autónomas), Madrid (Civitas), 1996 y RAZQUÍN LIZARRAGA, J. A.: "La apertura de oficinas de farmacia: el Real Decreto-Ley 11/1996, de 17 de junio", Actualidad Jurídica Aranzadi, núm. 262, 1996, págs. 1-4.

54 CUETO PÉREZ, M.: “Ordenación farmacéutica: competencias y funciones de las Comunidades Autónomas", cit., pág. 100.

55 Señalando que a tal situación coadyuvó decisivamente la STC 109/2003, de 5 de junio, HERNÁNDEZ SAN JUAN, I.: "La autorización administrativa de apertura de oficinas de 
un "frenético proceso legislativo por asumir competencias" cuyo resultante avoca a una situación técnicamente muy compleja y comparativamente muy diversificada ${ }^{56}$.

En una dura crítica que sirve para presentar el panorama actual se indica cómo, "a la falta de legislación básica clarificadora del modelo de oficinas de farmacia y de la necesaria concreción de los criterios de planificación, las Comunidades Autónomas se han lanzado a regular cada una a su forma -según el matiz político de sus órganos de gobierno- el régimen de las oficinas de farmacia. El resultado es un caos absoluto legislativo y una amalgama interminable de procedimientos. Basta comparar las distintas leyes aprobadas por las Comunidades Autónomas para comprobar que algunos aspectos esenciales de su regulación difieren de tal forma que han desdibujado las condiciones básicas garantizadas de la igualdad en el ejercicio de los derechos y en el cumplimiento de los deberes constitucionales que proclama el art. 149.1.1 ${ }^{\circ} \mathrm{CE}^{\prime \prime} 57$.

En esta dinámica, que lejos de encontrar corrección se acentúa ${ }^{58}$, habrá que situar la Ley 19/1998, de 15 de noviembre, de Ordenación y Atención Farmacéutica de la Comunidad de Madrid (y en concreto su art. 32, con las previsiones concordantes que al respecto figuran en el art. 3.1 de Decreto 115/1997, de 18 de septiembre), conscientes de que -por cuanto ahora interesa- su regulación sobre módulos de población y distancia no coincidirá con los existentes en otros territorios del Estado, pues si bien todos aparecen ajustados en lo fundamental a la norma básica estatal, diferirán de manera apreciable a la hora de concretar unos referentes tan abiertos como los que dispone el art. 2 LRSOF, a cuyo tenor:

“1. En desarrollo de lo que establece el artículo 103.3 de la vigente Ley 14/1986, General de Sanidad, de 25 de abril, y el artículo 88 de la Ley 25/1990, de 20 de diciembre, del Medicamento, y al objeto de ordenar la asistencia farmacéutica a la población, las Comunidades Autónomas, a las que corresponde garantizar dicha asistencia, establecerán criterios específicos de planificación para la autorización de oficinas de farmacia.

farmacia”, en AA.VV. (PAREJO ALFONSO, L. Dir.): Autorizaciones y licencias, hoy. Un análisis sectorial tras la Directiva de Servicios, Valencia (Tirant lo Blanch), 2013, págs. 646, 648 y 649.

56 FERNÁNDEZ GONZÁLEZ, F. J.: "La ordenación y planificación de las oficinas de farmacia en el Estado de las Autonomías", Revista Española de Administración Local y Autonómica, núm. 276, 1998, pág. 62; en parecido sentido, MESTRE DELGADO, J. F.: "La competencia normativa en materia de ordenación farmacéutica", Derecho y Salud, Vol. 5, núm. 2, 1997, págs. 205 y ss.

57 VILLALBA PÉREZ, F. L.: "La necesaria previsibilidad y estabilidad del ejercicio profesional del farmacéutico en la oficina de farmacia", cit., págs. 892 y 893.

58 Así las observaciones que al respecto realizan MUELAS TIRADO, J.: Régimen jurídico de apertura y actividad de las oficinas de farmacia, cit., págs. 75 y ss. o VIDAL CASERO, M. C.: "El desarrollo evolutivo de la reglamentación sobre garantías en los procedimientos de apertura de nuevas oficinas de farmacia", Revista General Informática de Derecho, núm. 1, 200, (recurso on line). 
La planificación farmacéutica se realizará de acuerdo con la planificación sanitaria. Las demarcaciones de referencia para la planificación farmacéutica serán las unidades básicas de atención primaria fijadas por las Comunidades Autónomas.

2. La planificación de oficinas de farmacia se establecerá teniendo en cuenta la densidad demográfica, características geográficas y dispersión de la población, con vistas a garantizar la accesibilidad y calidad en el servicio, y la suficiencia en el suministro de medicamentos según las necesidades sanitarias en cada territorio.

La ordenación territorial de estos establecimientos se efectuará por módulos de población y distancias entre oficinas de farmacia, que determinarán las Comunidades Autónomas, conforme a los criterios generales antes señalados. En todo caso, las normas de ordenación territorial deberán garantizar la adecuada atención farmacéutica a toda la población.

3. El módulo de población mínimo para la apertura de oficinas de farmacia será, con carácter general, de 2.800 habitantes por establecimiento. Las Comunidades Autónomas, en función de la concentración de la población, podrán establecer módulos de población superiores, con un límite de 4.000 habitantes por oficina de farmacia. En todo caso, una vez superadas estas proporciones, podrá establecerse una nueva oficina de farmacia por fracción superior a 2.000 habitantes.

No obstante lo dispuesto en el párrafo anterior, las Comunidades Autónomas podrán establecer módulos de población inferiores para las zonas rurales, turísticas, de montaña, o aquéllas en las que, en función de sus características geográficas, demográficas o sanitarias, no fuese posible la atención farmacéutica aplicando los criterios generales.

4. La distancia mínima entre oficinas de farmacia, teniendo en cuenta criterios geográficos y de dispersión ce la población será, con carácter general, de 250 metros. Las Comunidades Autónomas, en función de la concentración de la población, podrán autorizar distancias menores entre las mismas; asimismo, las Comunidades Autónomas podrán establecer limitaciones a la instalación de oficinas de farmacia en la proximidad de los centros sanitarios.

El cómputo de habitantes en las zonas farmacéuticas, así como los criterios de medición de distancias entre estos establecimientos, se regularán por las Comunidades Autónomas.

5. El cómputo de habitantes se efectuará en base al padrón municipal vigente, sin perjuicio de los elementos correctores que, en razón de las diferentes circunstancias demográficas, se introduzcan por las Comunidades Autónomas".

Sobre este patrón tan flexible, que se acomoda a la pérdida de la condición de básicos de los máximos y mínimos en población y distancia, el panorama de reparto competencial quedaría gráficamente establecido según se fija en la Tabla 2. 


\section{Tabla 2}

Requisitos necesarios para la autorización de apertura de farmacias. Pautas estatales y ámbito de competencia de las CC.AA.

\begin{tabular}{|c|c|}
\hline Criterio a tener en cuenta & Valor definido en la Ley 16/1997 \\
\hline Unidad territorial de referencia & Unidades básicas de atención primaria \\
\hline Base del cómputo de habitantes & Padrón municipal \\
\hline $\begin{array}{c}\text { Medición del cómputo de habitantes y } \\
\text { distancias }\end{array}$ & $\begin{array}{c}\text { Delegado a las Comunidades Autónomas } \\
\text { Distancia mínima entre farmacias }\end{array}$ \\
\hline $\begin{array}{c}\text { Excepciones a la distancia mínima } \\
\text { Cácter general: } 250 \mathrm{~m}\end{array}$ \\
\hline Módulo de población máximo & $\begin{array}{c}\text { Autónomas según la concentración de } \\
\text { población }\end{array}$ \\
\hline Módulo de población mínimo & Carácter general: $1 / 4000$ \\
\hline $\begin{array}{c}\text { Módulo de población para apertura de } \\
\text { farmacias adicionales }\end{array}$ & Carácter general: $1 / 2800$ \\
\hline Excepciones al módulo poblacional mínimo $1 / 2000$ \\
\hline Distancias mínimas a Centro de Salud & $\begin{array}{c}\text { A la baja según el criterio de las } \\
\text { Comunidades Autónomas de consecución }\end{array}$ \\
\hline
\end{tabular}

Fuente: GRANDA $(2017)^{59}$.

No podrá extrañar, por consiguiente, que abunden los estudios destinados a cada una de las Comunidades Autónomas ${ }^{60}$, e incluso que los análisis comparados lleven a

59 GRANDA, E.: “Ordenación farmacéutica y economía de las farmacias: conclusión y recomendaciones", Farmacia Profesional, Vol. 31, núm. 3, 2017, pág. 2.

60 Así, por ejemplo, los análisis previos de la primera Ley de Cataluña que efectuaron MARTÍN BAREA, M. P. y ESPINOSA RAMOS, E.: "Ley de Ordenación Farmacéutica de Cataluña”, Offarm, Vol. 11 núm. 6, 1996, págs. 40-42 o BEL PRIETO, E. y SUÑÉ ARBUSSÁ, J.M.: "Estudio crítico de la Ley de Ordenación Farmaceuta de Cataluña (I). La oficina de farmacia ( $1^{\text {a }}$ y $2^{\text {a }}$ parte)”, Offarm, Vol. 12, núms. 1 y 2, 1993, págs. 54-61 y 6369, respectivamente; CARRASCOSA SALMORAL, A: "Apertura de oficinas de farmacia en Andalucía", La Toga, núm. 138, 2002, págs. 27-28; VIDAL CASERO, M. M.: "La apertura de oficinas de farmacia en el País Vasco", El farmacéutico: profesión y cultura, núms. 210 y 225, 1998 y 1999, págs. 74-79 y 104-110, respectivamente; CERVERA SOTO, S.: "El modelo de atención farmacéutica en la legislación navarra", cit., págs. 1-8; AGRAZ PÉREZ-ENRÍQUEZ, L. y NAVARRO FUENTES, M.: "Apertura de oficinas de farmacia en la Comunidad de Madrid", Acofar, núm. 389, 2000, págs. 12-13; GAGO CABEZUDO, M. J.: La farmacia en Castilla La-Mancha. Incidencia normativa y social, Tesis Doctoral, Universidad Complutense de Madrid, 2002, en https://dialnet.unirioja.es/servlet/tesis?codigo=165953; o, en fin CARROBLES GARCÍA, J.: Manual práctico de apertura y gestión de farmacias en Castilla-La Mancha, Cuenca (Alfonsípolis), 2000. 
aludir a modelos61, proclamando las diferencias evidentes en la planificación (en algunas ocasiones con tal singularidad como para haber sido cuestionada su constitucionalidad porque, buscando una superior eficacia ${ }^{62}$ el "sistema de mínimos" al que tiende la Comunidad de Navarra se valoró como una desregulación encubierta ${ }^{63}$ ). Lejos de pretender tal comparativa, o siquiera el reflejo textual de los diferentes preceptos que ordenan la materia ${ }^{64}$ se quiere ofrecer al lector de este comentario una imagen gráfica del contexto plural en el cual aparece ubicada la norma madrileña llamada a resolver el caso, a fin de que pueda visualizar los diversos modelos de población adoptados y sus variantes no solo en la referencia a zonas urbanas, sino también semiurbanas, rurales, turísticas u otras especiales (Tabla 3); medios de prueba y criterios para el cómputo de la población, añadiendo a la referencia proporcionada por el padrón -y la certificación administrativa que en su caso se precise-, las fórmulas para contabilizar a la población de hecho no censada, la turística y/o la derivada de segundas residencias (Tabla 4), las variantes sobre distancias mínimas entre farmacias y respecto a centros sanitarios públicos (Tabla 5) y las condiciones para la creación de botiquines (Tabla 6).

61 A los que alude, por ejemplo, MUÑOZ PEREA PIÑAR, I.: Diferencias en las normativas autonómicas para la apertura de oficina de farmacia, Tesis Doctoral, Universidad Alfonso X el Sabio, 2017, en https://dialnet.unirioja.es/servlet/tesis?codigo=219567.

62 Así lo demuestra BARBARISI, I. et alii.: "A spatial analysis to evaluate the impact of deregulation policies in the pharmacy sector: Evidence from the case of Navarre", Health Policy, Vol. 123, núm. 11, 2019, págs.1108-1115.

63 Comentado en el ATC 62/2004, de 24 febrero de 2004, que resuelve la cuestión de inconstitucionalidad suscitada por el Tribunal Superior de Justicia de Navarra frente a cuanto disponen los arts. 24.3, 26 y 27 de la Ley Foral 12/2000, de Atención Farmacéutica, LARRUMBE SANMARTÍN, F.: "Liberalización de la apertura de oficinas de farmacia: constitucionalidad de la Ley Foral Navarra", Actualidad Jurídica Aranzadi, núm. 623, 2004, BIB \2004\382.

64 En tal empeño el notable esfuerzo histórico que realiza SUÑÉ ARBUSSA, J.M. y BEL PRIETO, E: "La ordenación farmacéutica en las Comunidades Autónomas. Determinación del número de farmacias (I). Módulos poblacionales y distancias", Offarm, Vol. 19, núm. 1, 2000, págs. 106-113; "La ordenación farmacéutica en las Comunidades Autónomas. Determinación del número de farmacias (II). Estudio comparativo", Offarm, Vol. 19, núm. 2, 2000, págs. 124-134; o "La ordenación farmacéutica en las Comunidades Autónomas (III). Medición de distancias”, Offarm, Vol. 19, núm. 5, 2000, págs. 152-164. 


\section{Tabla 3}

\section{Módulos de población}

\begin{tabular}{|c|c|c|c|c|c|}
\hline 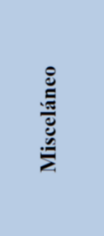 & 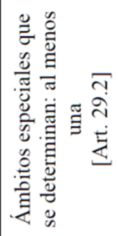 & 1 & 1 & 1 & 1 \\
\hline 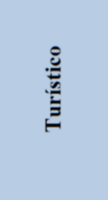 & 1 & 1 & 1 & I & 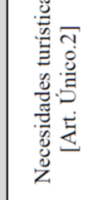 \\
\hline $\bar{z}$ & 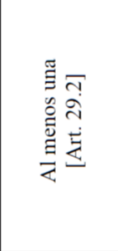 & 1 & 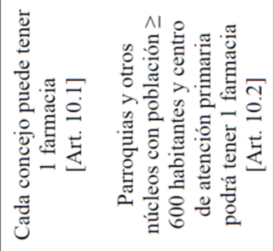 & 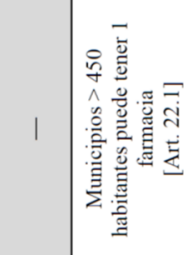 & 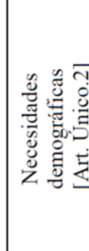 \\
\hline 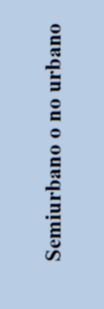 & 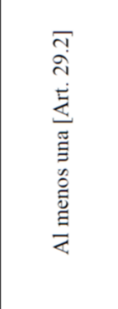 & 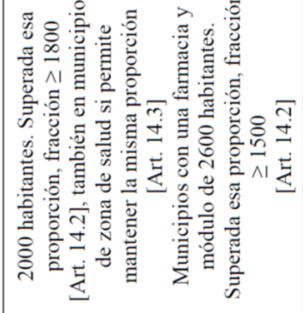 & 1 & 1 & 1 \\
\hline 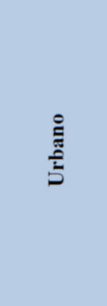 & 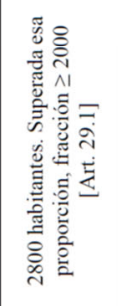 & 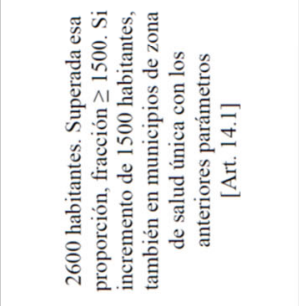 & 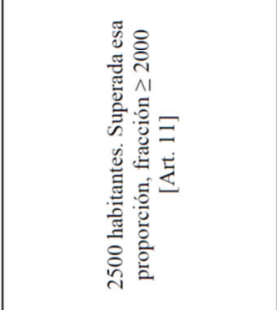 & 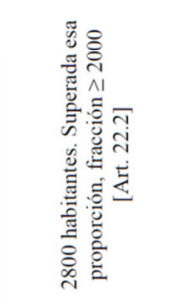 & 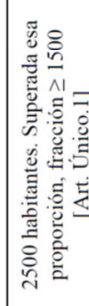 \\
\hline$/$ & 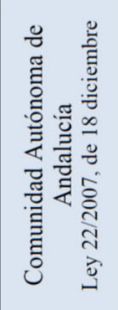 & 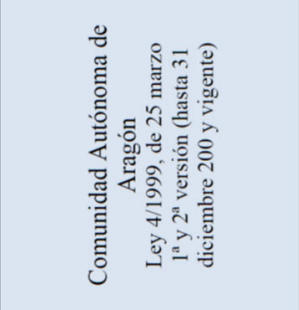 & 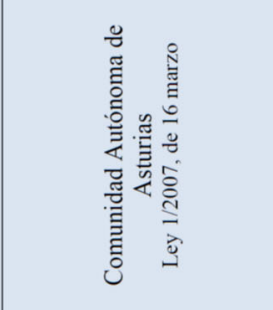 & 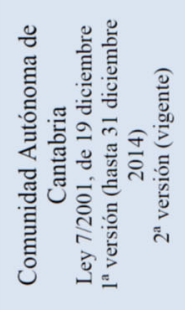 & 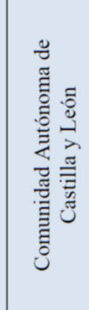 \\
\hline
\end{tabular}




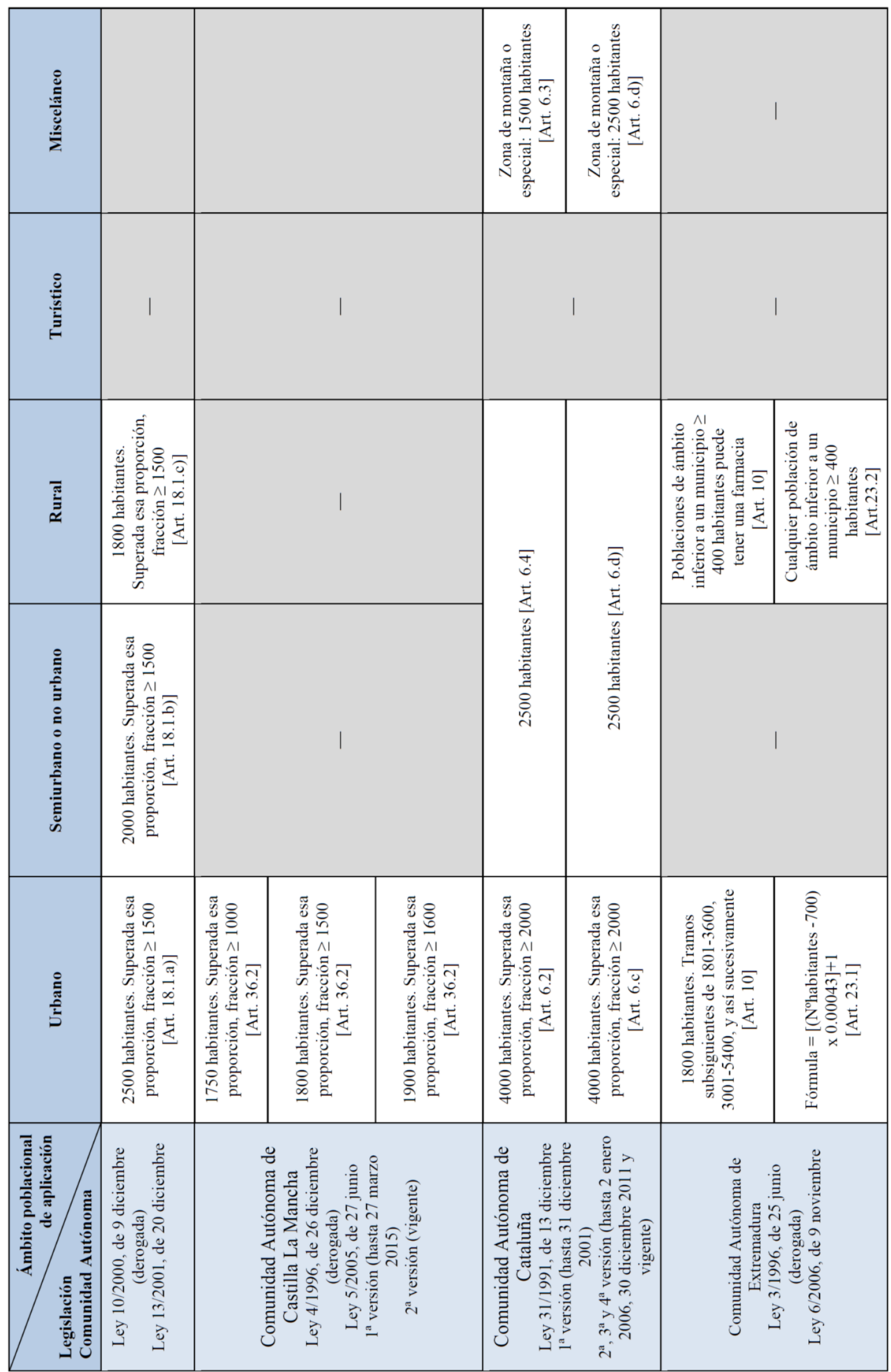




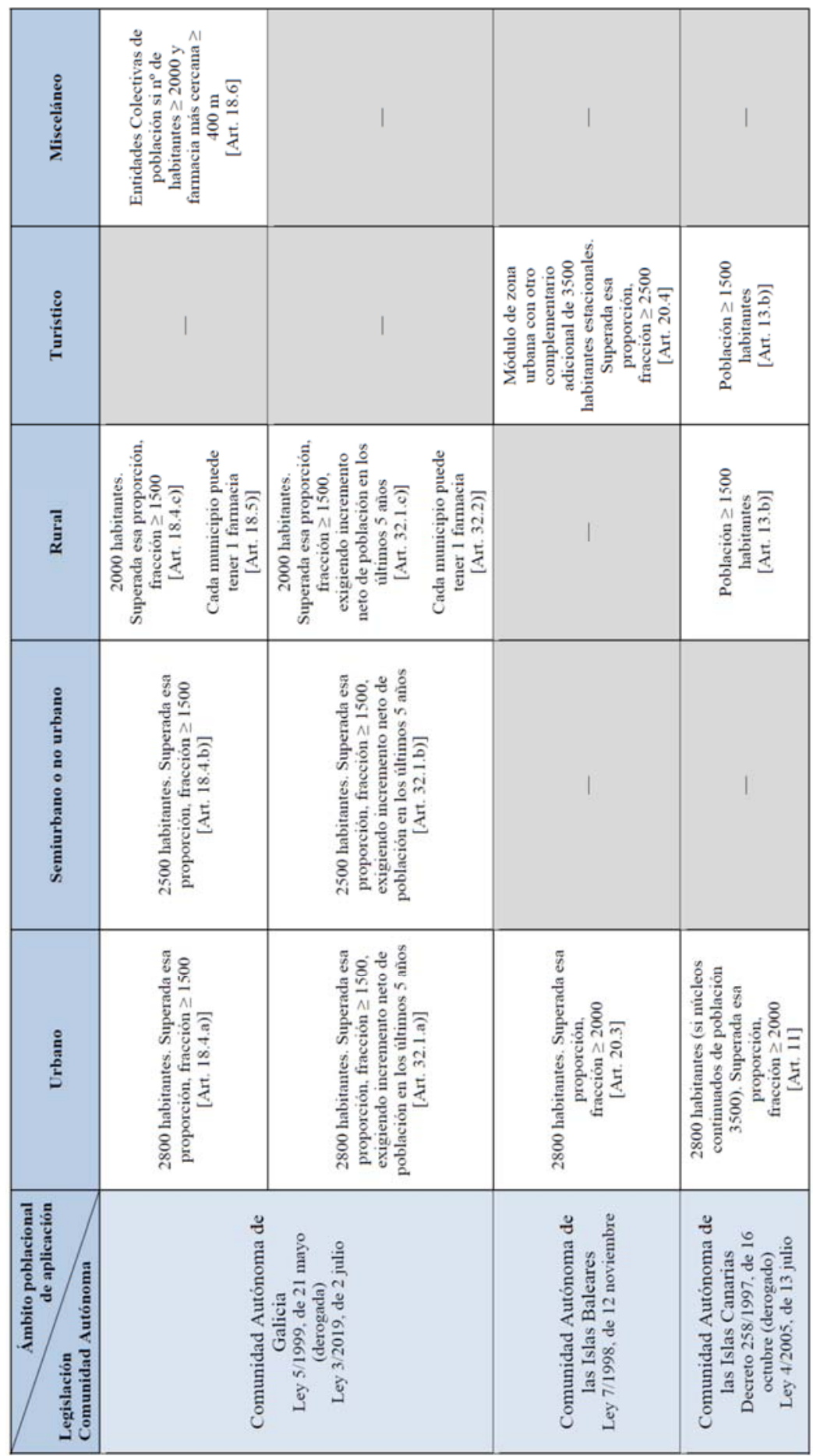




\begin{tabular}{|c|c|c|c|c|c|}
\hline 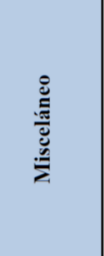 & 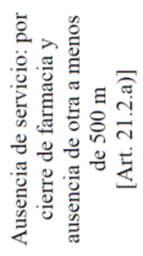 & | & I & 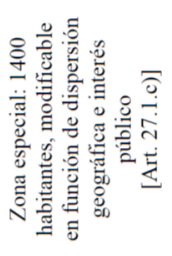 & 1 \\
\hline 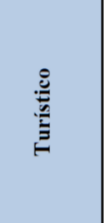 & 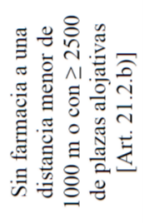 & | & 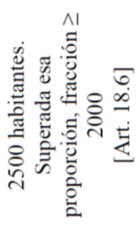 & I & 1 \\
\hline$\underset{\underline{\underline{x}}}{\overline{\underline{x}}}$ & 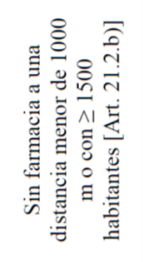 & 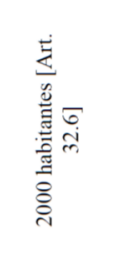 & 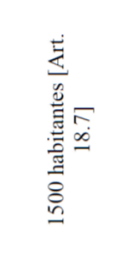 & 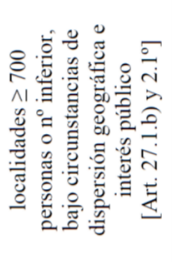 & 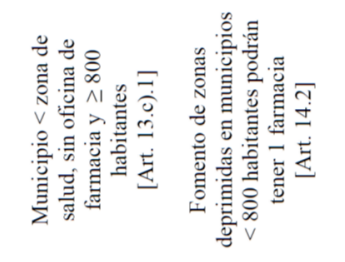 \\
\hline 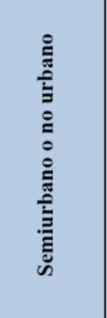 & & I & 1 & 1 & 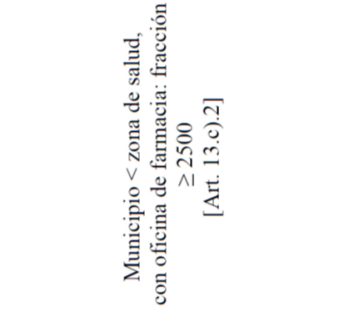 \\
\hline 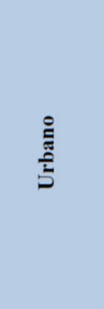 & 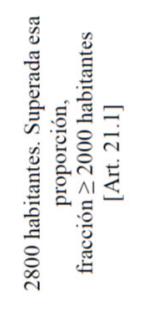 & 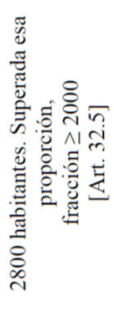 & 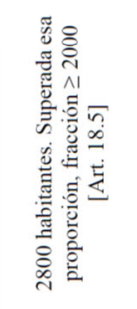 & 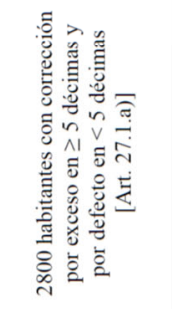 & 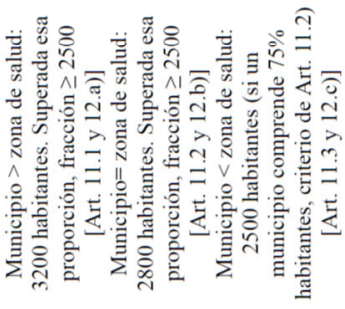 \\
\hline / & & 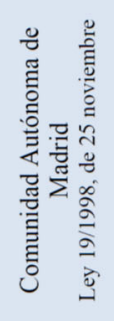 & 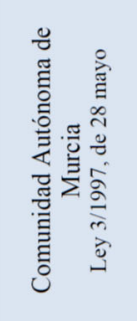 & 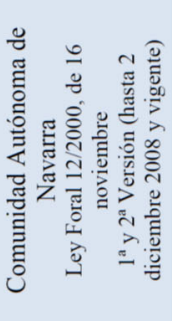 & 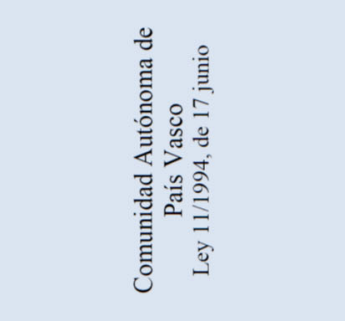 \\
\hline
\end{tabular}




\begin{tabular}{|c|c|c|c|c|c|}
\hline 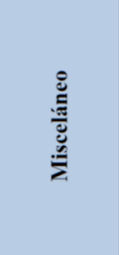 & 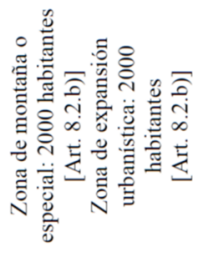 & 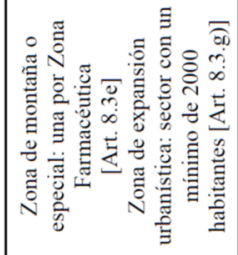 & \multicolumn{2}{|c|}{ 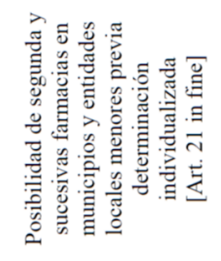 } & \multirow{4}{*}{1} \\
\hline$\frac{8}{\frac{8}{20}}$ & 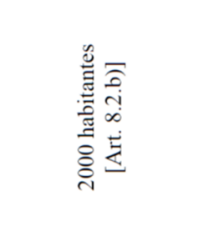 & 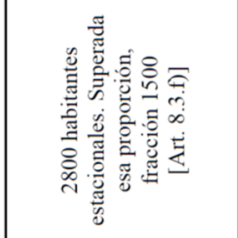 & \multicolumn{2}{|c|}{ 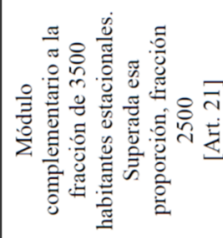 } & \\
\hline$\overline{\widetilde{I}}$ & 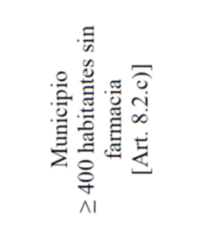 & 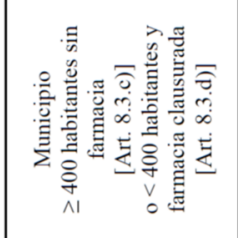 & 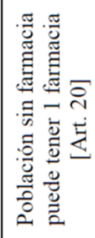 & 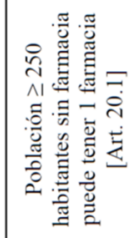 & \\
\hline 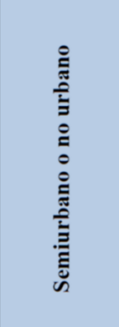 & 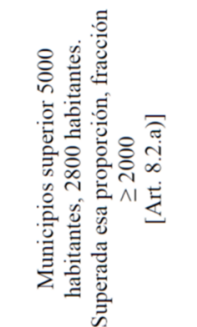 & 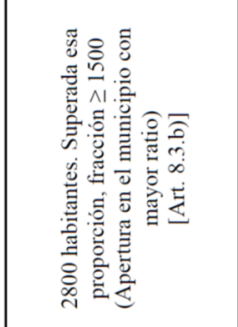 & \multicolumn{2}{|r|}{ I } & \\
\hline 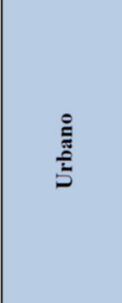 & 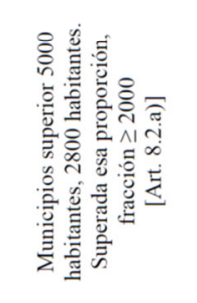 & 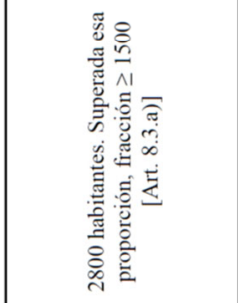 & \multicolumn{2}{|c|}{ 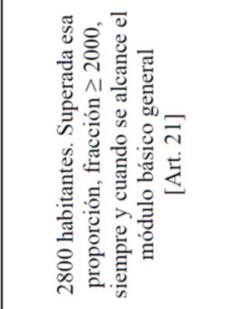 } & 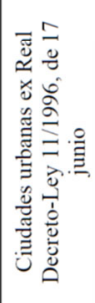 \\
\hline 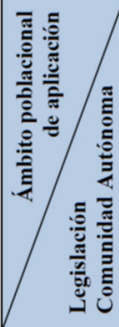 & \multicolumn{2}{|c|}{ 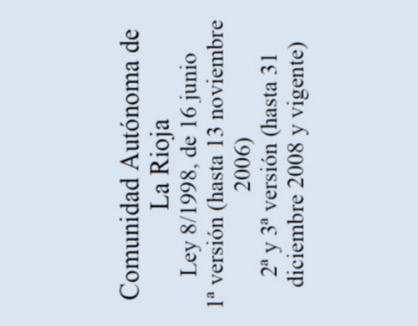 } & \multicolumn{2}{|c|}{ 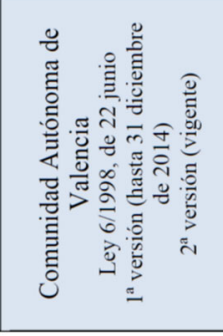 } & 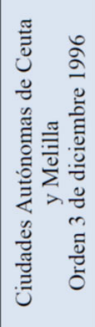 \\
\hline
\end{tabular}

Fuente: Elaboración propia. 


\section{Tabla 4}

\section{Bases para el cómputo de la población}

\begin{tabular}{|c|c|c|c|c|c|c|c|c|}
\hline 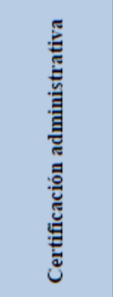 & 1 & 1 & 1 & 1 & I & 1 & I & 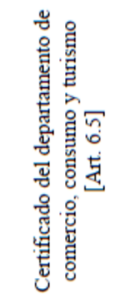 \\
\hline 总 & 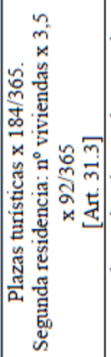 & 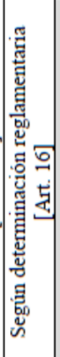 & I & 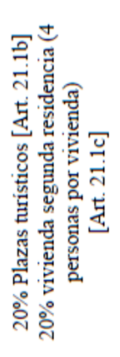 & I & 1 & I & 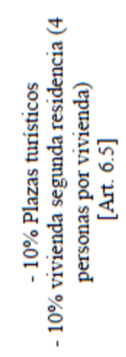 \\
\hline 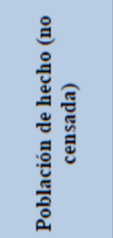 & 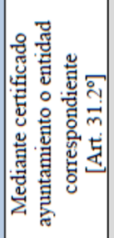 & 1 & 1 & I & I & 1 & I & 1 \\
\hline 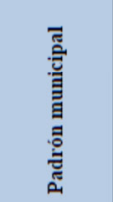 & $\begin{array}{l}\overrightarrow{7} \\
\underset{m}{m} \\
\text { 莡 }\end{array}$ & 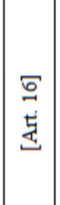 & $\begin{array}{l}\Xi \\
\Xi \\
\text { 离 }\end{array}$ & 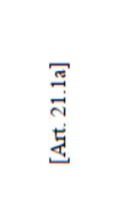 & I & 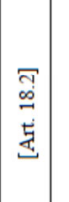 & $\begin{array}{l}\overrightarrow{7} \\
\text { m } \\
\text { 恶 }\end{array}$ & 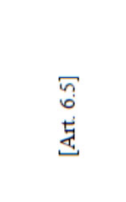 \\
\hline 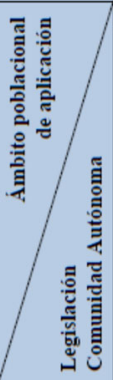 & 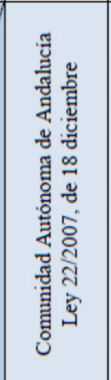 & 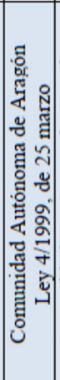 & 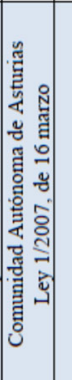 & 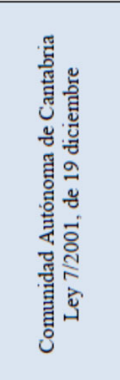 & $\begin{array}{l} \\
\\
0 \\
0\end{array}$ & 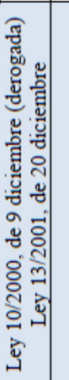 & 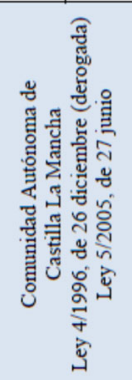 & 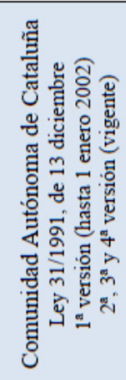 \\
\hline
\end{tabular}




\begin{tabular}{|c|c|c|c|c|c|c|c|c|c|c|}
\hline 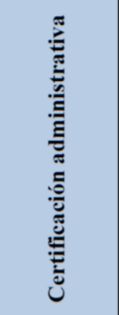 & 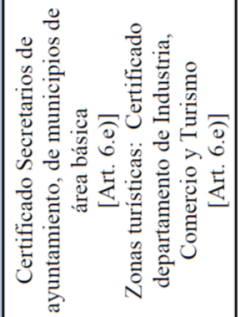 & 1 & | & 1 & 1 & I & | & 1 & 1 & $\begin{array}{l}\sigma \\
\infty \\
\stackrel{\infty}{E} \\
\dot{E}\end{array}$ \\
\hline 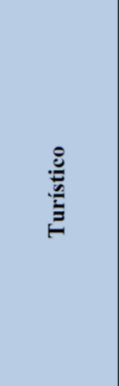 & 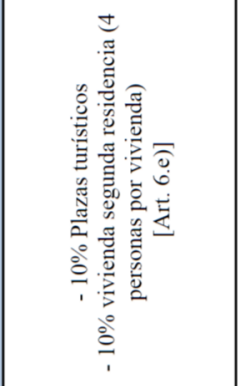 & 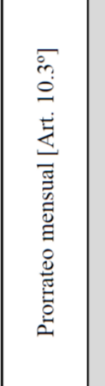 & I & 1 & 1 & 1 & 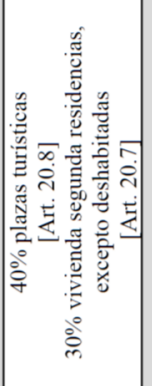 & 1 & 1 & 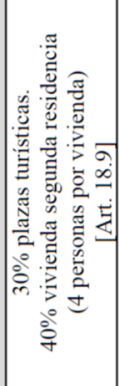 \\
\hline 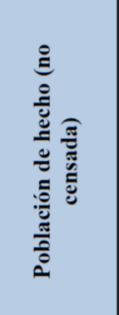 & 1 & 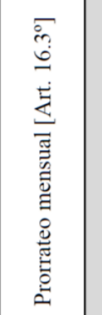 & I & 1 & 1 & 1 & 1 & 1 & 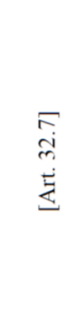 & 1 \\
\hline 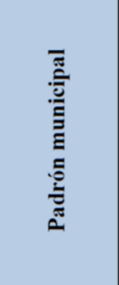 & 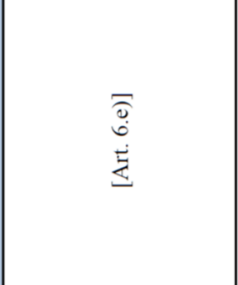 & 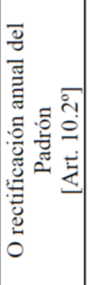 & $\begin{array}{l}\bar{m} \\
\stackrel{7}{3} \\
\dot{E}\end{array}$ & $\begin{array}{l}\infty \\
\infty \\
\infty \\
\dot{E} \\
\leq\end{array}$ & $\begin{array}{l}\bar{m} \\
\tilde{j} \\
\tilde{y}\end{array}$ & 1 & 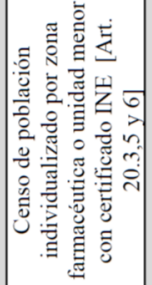 & I & $\begin{array}{l}\text { तi } \\
\text { d } \\
\text { E }\end{array}$ & $\begin{array}{l}\infty \\
\infty \\
\infty \\
\dot{E}\end{array}$ \\
\hline 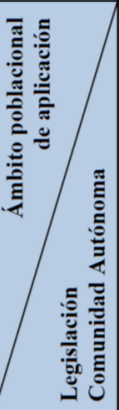 & & 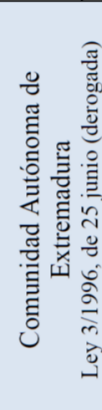 & 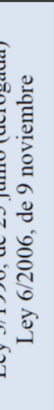 & 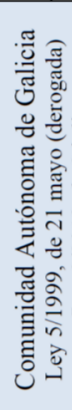 & 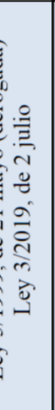 & 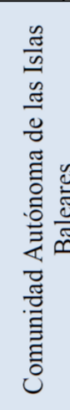 & 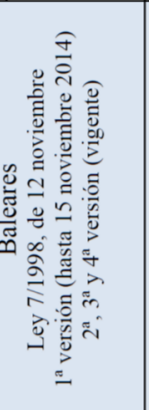 & 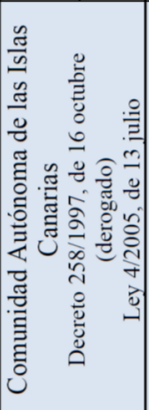 & 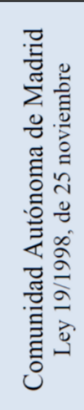 & 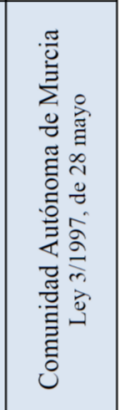 \\
\hline
\end{tabular}




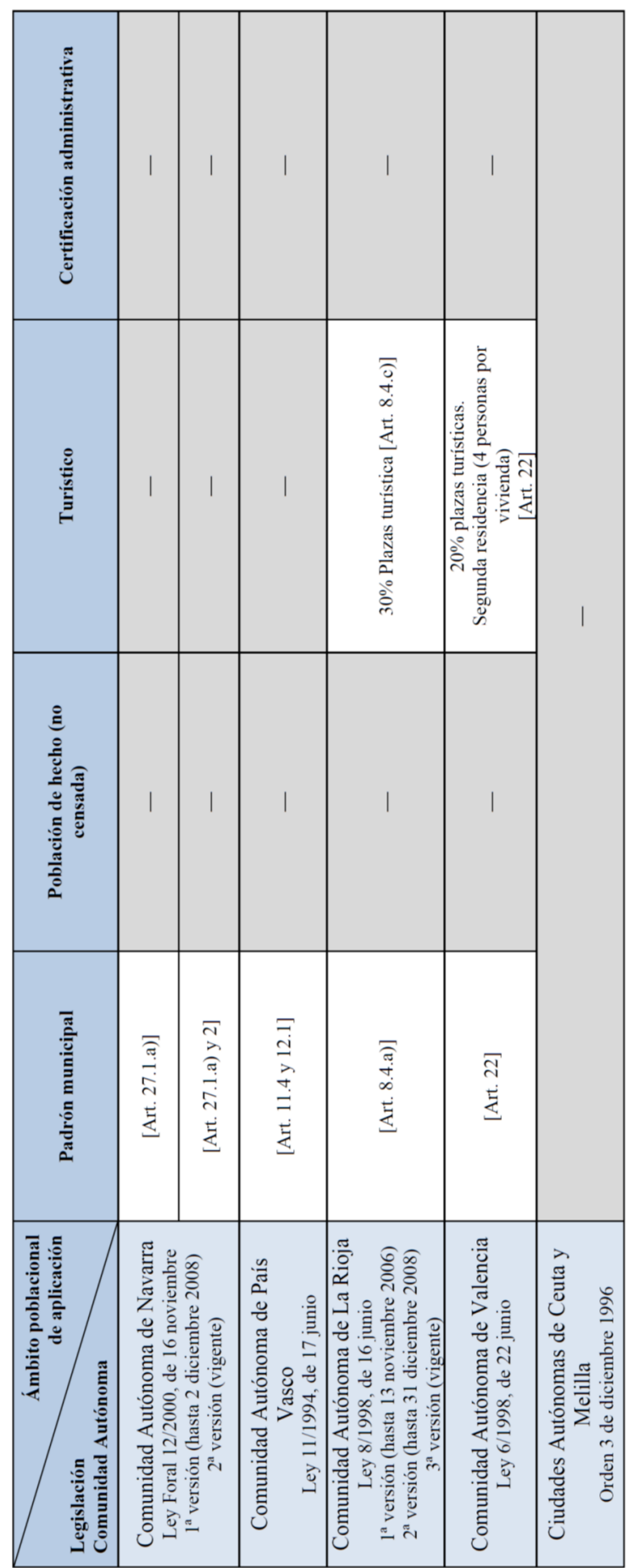

Fuente: Elaboración propia. 
144 Juan José Fernández Domínguez, Juan José García Vieitez y Guillermo Domínguez Fernández

Tabla 5

Distancia mínima entre farmacias y respecto a centro sanitarios públicos

\begin{tabular}{|c|c|c|c|c|c|c|c|c|}
\hline 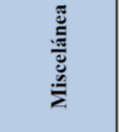 & 1 & 1 & 1 & I & 1 & 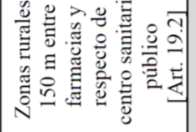 & | & 1 \\
\hline 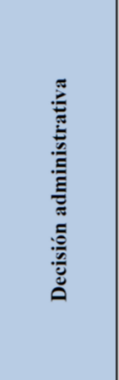 & 1 & I & 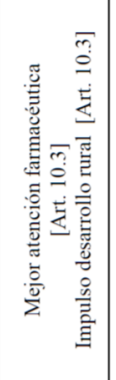 & 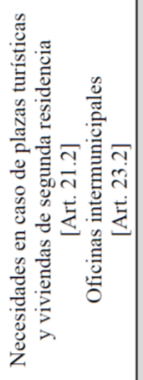 & 1 & 1 & | & | \\
\hline 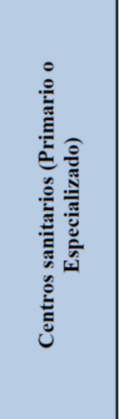 & 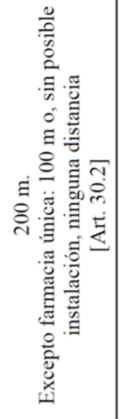 & 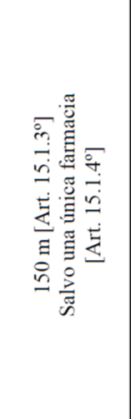 & 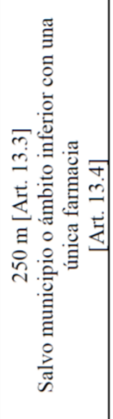 & 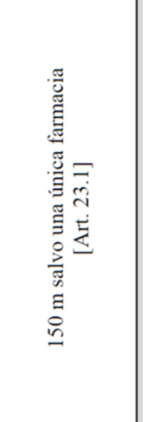 & 1 & 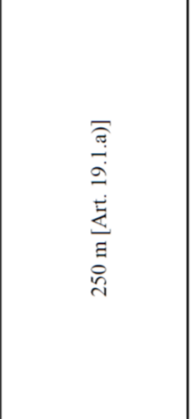 & 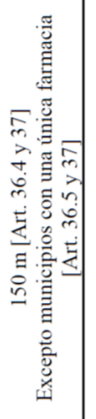 & 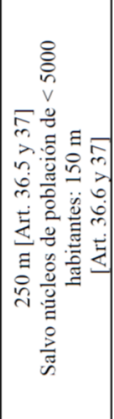 \\
\hline 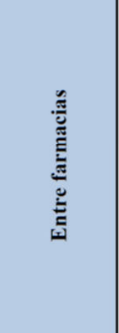 & 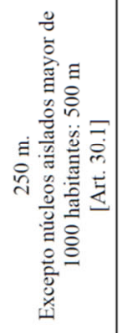 & 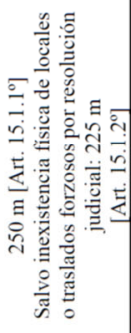 & 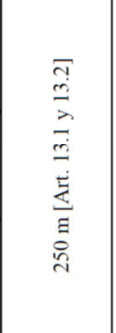 & 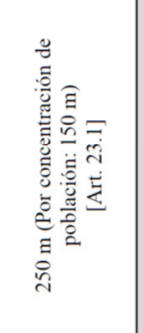 & 1 & 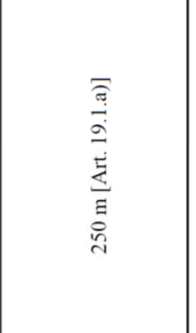 & 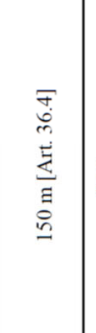 & 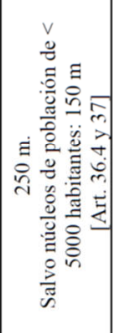 \\
\hline 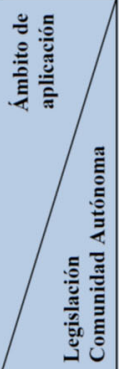 & 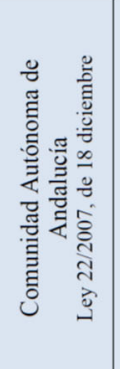 & 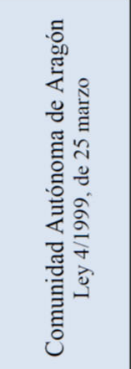 & 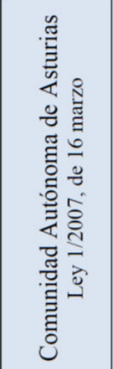 & 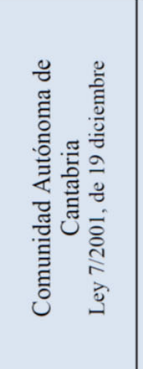 & & 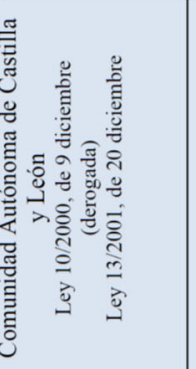 & 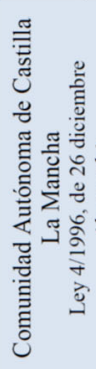 & 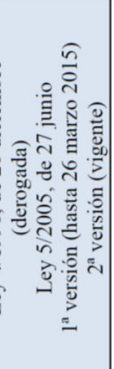 \\
\hline
\end{tabular}




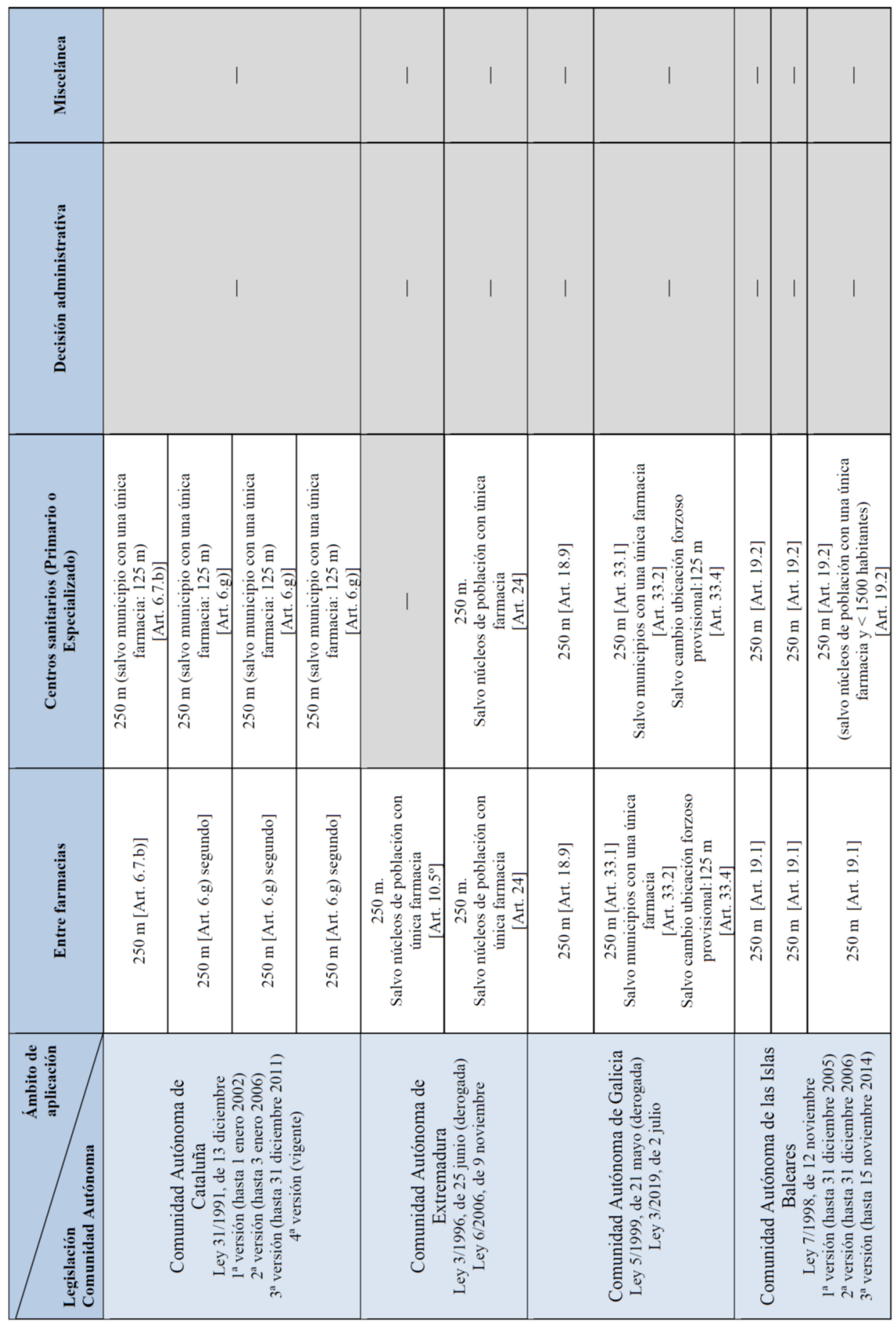




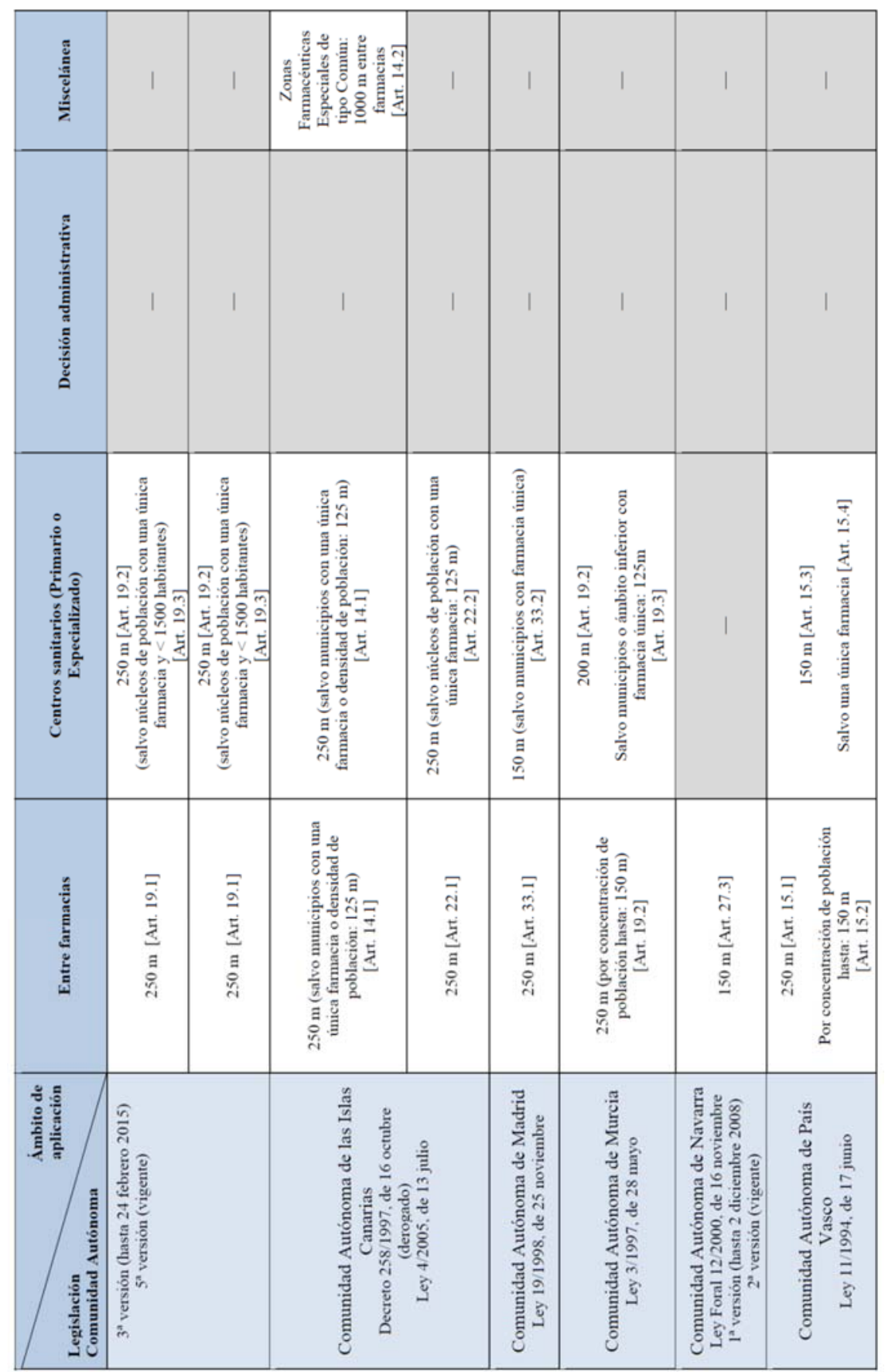




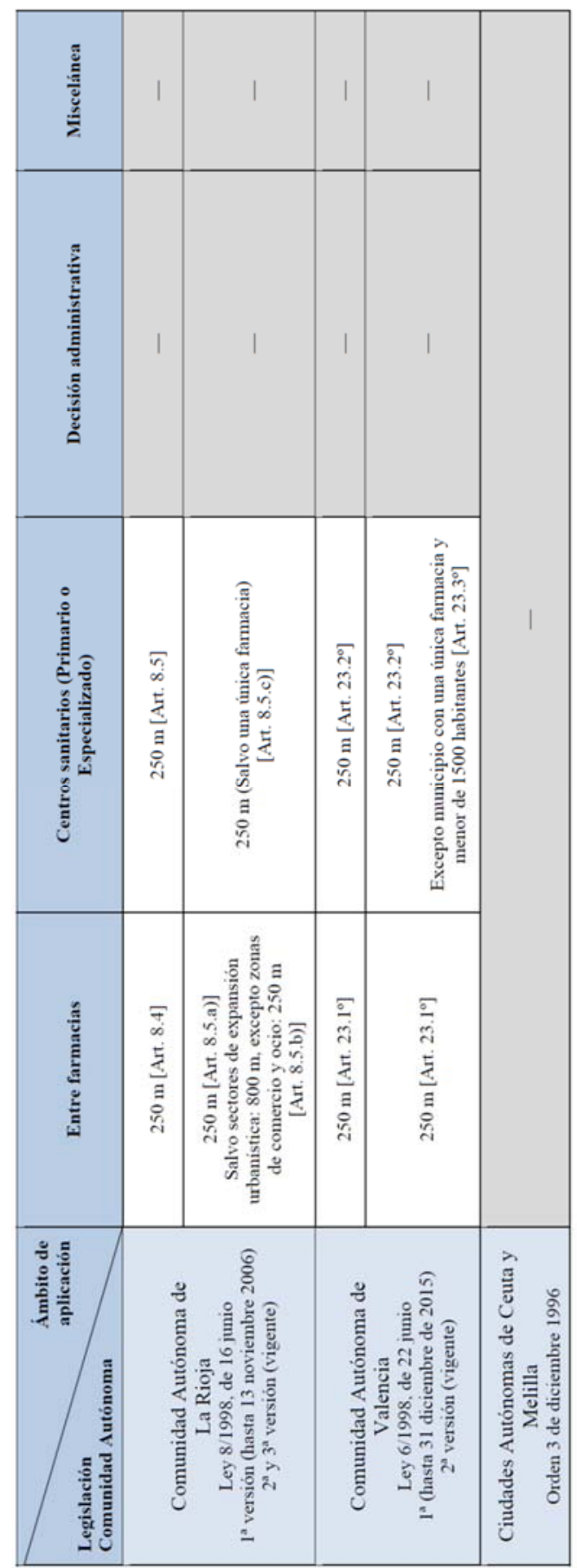

Fuente: Elaboración propia. 
148 Juan José Fernández Domínguez, Juan José García Vieitez y Guillermo Domínguez Fernández

\section{Tabla 6}

\section{Condiciones para la creación de botiquines}

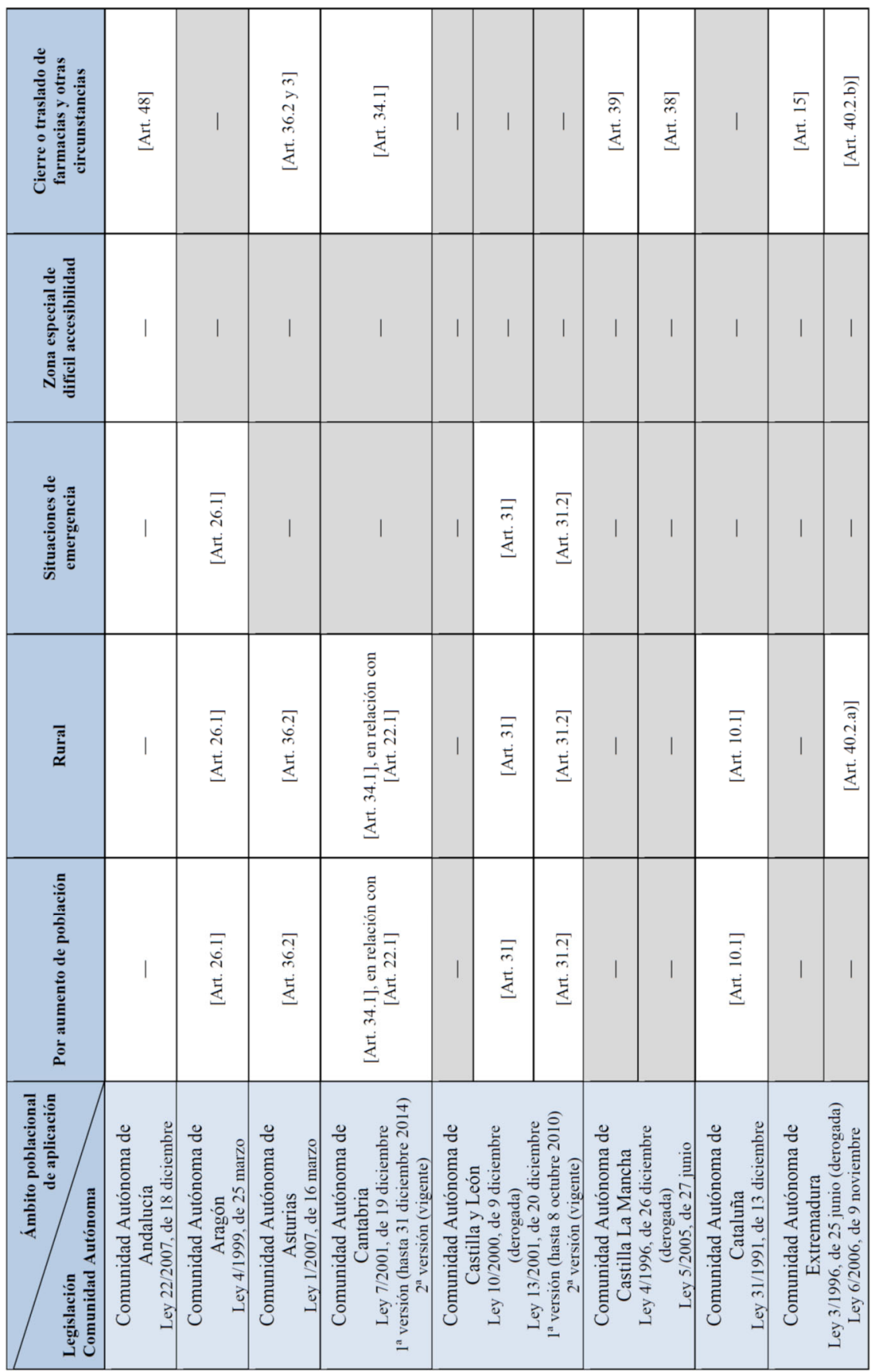




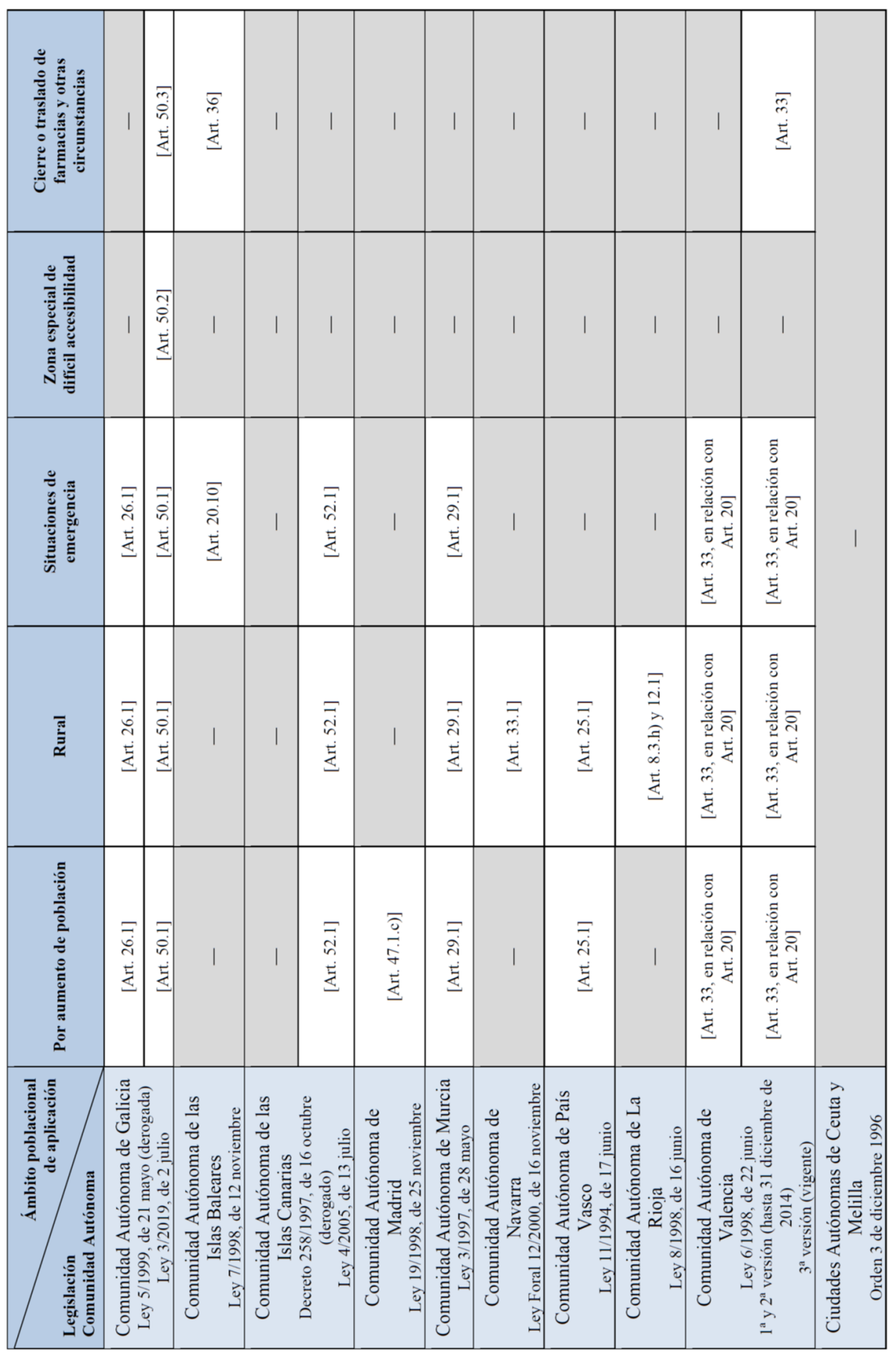

Fuente: Elaboración propia. 


\section{Aspectos principales de la jurisprudencia sobre la apertura de oficinas de farmacia. La solución al caso estudiado}

Una exposición del contexto donde se desarrolla la norma madrileña sometida a consideración no quedaría completa si, al tiempo, no se proporciona una visión sucinta de las principales cuestiones que ha suscitado su aplicación a lo largo del tiempo.

Para ello se recurre a una selección de los cientos de pronunciamientos en la materia que han surgido del Tribunal Supremo, y ello aun siendo conscientes de que, aun cuando a efectos del recurso de casación las cuestiones referidas a la apertura de farmacia son de cuantía indeterminada ${ }^{65}$, su importancia ha disminuido de manera notable, no en vano "no resulta competencia del Tribunal Supremo revisar en casación la interpretación y aplicación del ordenamiento jurídico autonómico, que en exclusiva corresponde a la Sala sentenciadora del Tribunal Superior de Justicia" ${ }^{66}$. Con todo, el examen de cuanto puede adolecer de inmediata actualidad presenta una doble ventaja: de un lado, la seguridad jurídica de un parecer uniforme, frente a la diversidad de criterios que tantas veces sostienen los juzgadores autonómicos; de otro, el dato a partir del cual la posición del Tribunal Supremo es continuamente recordada por aquellos, para mostrar cómo los grandes temas se vienen repitiendo desde hace tiempo $\mathrm{y}$, aunque los matices no dejen de enriquecerlos, el criterio jurisprudencial pacientemente decantado sigue siendo la principal referencia también en este ámbito.

Bajo tal planteamiento, cabría enunciar el siguiente elenco de aspectos fundamentales de interés, convertidos en las principales cuestiones controvertidas:

1.- Las múltiples situaciones de concurrencia que pueden afectar a las autorizaciones de apertura, e indirectamente tiene que ver con el cómputo de población afectado en un procedimiento en concreto, como pudieran ser si el núcleo identificado coincide o no parcialmente con otro que ya sirvió para anteriores autorizaciones -o llevo a anulaciones $^{67}$ - por vía administrativa o judicial ${ }^{68}$; si la solicitud se ve afectada por otras anteriores aún pendientes de decisión o por expedientes en trámite ${ }^{69} \mathrm{o}-$ sin perjuicio de otras situaciones menos corrientes $^{70}$ - si media o no colisión entre el proceso de autorización de apertura sobre una base poblacional dada y los traslados

65 AATS 29 marzo 2007 (rec. 9798/2003) y 25 febrero 2010 (rec. 5609/2009) y STS 16 julio 2014 -dos- (rec. 3535/2012 y 3459). excepcionales de habitantes agregados de otro -y distinto- núcleo farmacéutico en SSTS 30 septiembre 1987 (s/rec.), 5 diciembre 1995 (rec. 1106/1992) o 7 abril y 20 mayo 1998 (rec. 8133/1994 y 4458/1992).

69 SSTS 8 junio 1999 (rec. 4711/1993) o 29 mayo y 7 octubre 2009 (rec. 3534/2007 y 2416/2006).

70 Sirvan, por ejemplo, las interesantes muestras que proporcionan las SSTS 23 febrero 1994 (rec. 13548/1991), 18 octubre 1999 (rec. 7256/1993) o 28 marzo 2006 (s/rec.). 
de oficinas que aún no han culminado satisfactoriamente o han sido abiertos en paralelo o con posterioridad ${ }^{71}$.

Frente a pareceres previos de signo muy diverso, durante la primera década del siglo se afirmó una doctrina reiterada a cuyo tenor, en todas estas situaciones de conflicto, será preciso estar al momento y circunstancias de cada petición y a la prioridad de solicitudes en el tiempo ${ }^{72}$.

2.- De continuo invocado, el principio "pro apertura" o "pro libertate" (vinculado tanto al derecho a la protección de la salud -art. $43 \mathrm{CE}$ - como al principio de libertad de empresa -art. $38 \mathrm{CE}-\mathrm{y}$, a la postre, al criterio de "favor libertatis" que aspira a conducir a la igualdad real de los ciudadanos y los grupos sociales -art. 9.2 CE- ${ }^{73}$ ) constituye "necesario punto de partida" que ha de ordenar la apertura de farmacias; vinculado, siempre, al beneficio de los administrados, quienes así verán asegurada y notoriamente mejorada la dispensación de productos farmacéuticos ${ }^{74}$.

Con todo, esta primacía del servicio público (ocasionalmente concebida como un "principio de economía"), de indudable trascendencia por las ocasiones en que así se ha apreciado judicialmente ${ }^{75}$, dista de alcanzar la vis expansiva a la cual parece apuntar su propia denominación.

El Tribunal Supremo sienta a este respecto que sirve para resolver casos dudosos o situados en el límite, según ocurre, por ejemplo, cuando es escasa la diferencia entre los habitantes requeridos y la cifra acreditada, lo cual pudiera llevar a considerar que "de forma aproximada se cumple" "76, a deducir que el volumen real podría alcanzar esa cifra ${ }^{77} \mathrm{o}$, incluso, a inferir que incrementos futuros llevarán de manera clara y

71 Entre muchísimas, y además de ser los supuestos que sirven de base fundamental a la solución jurisprudencial unificada durante los primeros años del siglo XXI, valgan los ejemplos preclaros que muestran las SSTS 15 octubre 1992 (rec. 6245/1990), 20 enero 1993 (rec. 10978/1990) o 15 julio 2008 (rec. 5365/2005).

72 SSTS 20 septiembre y 20 noviembre 2000 (rec. 7937/1994 y 1549/1995), 10 mayo y 4 junio 2002 (rec. 5112/1997 y 6297/1997), 3 marzo 2003 (rec. 8812/1998), 24 abril 2007 (rec. 7809/2004), 27 enero y 17 marzo 2009 (rec. 4419/2006 y 2453/2006) o, recopilando un importante acervo que condensa la idea, 29 octubre 2012 (rec. 1035/2011).

73 Sobre el entronque constitucional del principio, por todas, STS 8 marzo 1996 (rec. 9210/1992).

74 Tal consideración, remarcada de modo adecuado, en SSTS 28 mayo 2003 (rec. 2631/2012) y 3 noviembre 2014 (rec. 3582/2013).

$75 \mathrm{Su}$ asentamiento, en una selección significativa, permite remitir a las SSTS 4 marzo 1985 (s/rec.); 6 octubre 1987 (s/rec.); 27 diciembre 1988 (s/rec.); 4 junio y 24 octubre 1990 (ambas s/rec.); 27 mayo 1991 (s/rec.); 3 octubre, 12 noviembre y 16 diciembre 1992 (rec. 692/1988, 655/1990 y 8616/1991); 14 abril 1994 (rec. 1180/1992); 25 julio 1995 (rec. 3396/1990); 29 enero 1997 (s/rec.); 31 enero, 26 febrero y 22 marzo 2002 (rec. 6195/1996 y 8933/1996); 1 marzo 2004 (rec. 4662/2001) o, por no seguir, 6 octubre 2008 (rec. $7106 / 2005)$.

76 STS 26 enero 2010 (rec. 5110/2008).

77 SSTS 12 noviembre 1992 (rec. 9450/1990), 14 octubre 1998 (rec. 9683/1992) o 5 noviembre 2003 (rec. 7015/1999). 
segura a superarla ${ }^{78}$. En modo alguno puede ser utilizada, sin embargo, para alterar el régimen jurídico establecido o solventar un supuesto que incumple notoriamente las exigencias $^{79}$; tampoco -por supuesto- para derogar el sistema de intervención administrativa o excluir requisitos a los que la norma supedita la procedencia de la apertura de farmacias ${ }^{80}$.

De este modo, y además de su aplicación en los supuestos ya reseñados de dudas en cuanto a los límites de población, cabrá dar cuenta de cómo su expresión más numerosa y acabada se ha venido encontrando en las excepciones a la exigencia de cubrir los umbrales de personas que permiten descubrir núcleos de población dotados de cierta homogeneidad y a los cuales atribuir carácter diferencial respecto del resto del casco urbano para autorizar una oficina de farmacia ${ }^{81}$.

De este modo, se vino a afirmar como regla la relativa a reconocer la continuidad del núcleo urbano (mientras este fue el parámetro utilizado, aun cuando sus problemas se trasladan, mutatis mutandis. a los nuevos referentes dentro de las zonas farmacéuticas, zonas de salud, zonas urbanas básicas, etc. ${ }^{82}$ ), sin cabida para invocaciones a una simple mayor facilidad o comodidad, pues "no cabe que sea diferenciado de manera artificial cuando no aparece dotado de verdadera sustantividad o independencia frente al resto de la población urbana" ${ }^{" 3}$. Para aplicar la excepción procederá exigir, por ende,

78 STS 24 junio 2002 (rec. 5122/1997).

79 SSTS 15 junio 1992 (rec. 6795/1990), 20 marzo 1995 (rec. 453/1992), 26 junio 1996 (rec. 1223/1994), 14 octubre 1998 (rec. 9683/1992), 17 enero y 30 mayo 2001 (rec. 4521/1995 y 3811/1995), 7 octubre 2003 (rec. 4473/1999), 1 marzo 2004 (rec. 4662/2001) o 24 mayo y 7 octubre 2005 (rec. 2534/2003 y s/rec.).

80 STS 8 marzo 2002 (rec. 2635/1997). En aplicación del criterio se sienta, por ejemplo, que, como regla, no cabrá utilizar la equiparación o analogía entre municipios y entidades inferiores al municipio para aplicar la norma que corresponda en cada ocasión, SSTS 1 octubre 1997 (rec. 7617/1994), 23 febrero 2000 (rec. 2986/1994) o 20 octubre 2003 (rec. $888 / 1999)$.

81 Interesante la síntesis que acomete POU VIVER, T.: "Nuevo concepto jurisprudencial de núcleo a efectos de apertura de farmacia”, Revista Española de Derecho Administrativo, núm. 96, 1997, págs. 603-608.

82 Baste para comprobarlo con revisar el razonamiento contenido en la STS abril 2005 (rec. 989/2003). Con carácter general, en relación con las zonas farmacéuticas, por ejemplo, SSTS 5 junio 2012 (rec. 6246/2010) o 15 septiembre 2015 (rec. 3727/2013); por referencia a las zonas básicas de salud, SSTS 2 junio 2009 (rec. 4335/2006) y 23 febrero 2010 (rec. 2594/2008); atendiendo a la delimitación de un área urbana básica, SSTS 24 enero 2012 (rec. 1052/2009) y 17 marzo 2016 (rec. 2151/2014).

83 SSTS, Sala Especial del art. 61 LOPJ, 19 octubre 1990 (rec. 196/1989) y SSTS 3 abril 1984 (s/rec.); 20 junio 1990 (s/rec.); 10 enero 1993 (rec. 10985/1990); 3 mayo 1999 (rec. 5616/1993); 12 abril y 24 mayo 2000 (rec. 4220/1994 y 5528/1994); 19 febrero, 13 marzo, 9 octubre y 20 noviembre 2001 (rec. 4019/1995, 6752/1995, 3245/1996 y 3378/1996); 25 marzo, 3 abril, 13 noviembre y 4 y 20 diciembre 2002 (rec. 9046/1996, 2075/1997, $855 / 1998,4189 / 1998$ y 4115/1998); 14 enero y 8 y 21 octubre 2003 (rec. 8776/1998, s/rec. y 3568/2000); 3 febrero, 1 marzo, 11 mayo, 9 junio y 28 septiembre 2004 (rec. 2834/2001, 4662/2001, 3482/1999, 7225/2001 y 3541/2001); 9 febrero, 15 marzo, 20 abril, 29 junio, 20 julio y 10 octubre 2005 (rec. 2372/2002, s/rec., 8183/2002, 2143/2003, s/rec. y 1148/2003); 23 marzo, 6 y 10 mayo y 4 y 10 octubre 2006 (s/rec., s/rec., s/rec., 3806/2004 
que se acredite por una única vez ${ }^{84}$-pues no cabrá aplicar dos veces la misma ${ }^{85}$, ya la presencia de un obstáculo natural que represente una notoria molestia o incomodidad en el traslado desde el núcleo separado hasta aquel donde está(n) ubicada(s) otra(s) oficina(s) de farmacia ${ }^{86}$, ya la existencia de un peligro cierto ocasionado por un obstáculo artificial (con singular relieve el tráfico o circulación intensa) ${ }^{87}$, ya la distancia excesiva hasta las farmacias más próximas u otras circunstancias análogas (entre las cuales destaca la dispersión en la población) capaces de justificar en el caso concreto esas razones de servicio necesarias para superar las dificultades reales en el acceso a la prestación tan básica ${ }^{88}$.

3.- Determinación del dies a quo a partir del cual procede computar la variación de población que, por incremento, está llamada a permitir la apertura de una farmacia, así como aquel que habrá de servir para tomar la referencia del número de personas y verificar si concurren o no los parámetros legales exigidos.

Partiendo de la necesidad de utilizar magnitudes homogéneas en todo momento (en particular por cuanto hace al cómputo de la población de hecho, para así eludir "combinaciones interesadas entre población de hecho y de derecho") ${ }^{89}$, la fecha de la cual se ha de partir para considerar el número de habitantes debe venir dada, como regla, por la del censo correspondiente al año en que se hubiera procedido a la apertura de la última farmacia ${ }^{90}$. Con todo, y en función de las circunstancias en presencia, se ha entendido que también procede considerar el padrón existente al momento de la autorización concedida en los supuestos de que, por un lado, con la aplicación de la regla se produzca un doble cómputo del incremento de la población, de manera que

y 3100/2004); 18 mayo 2007 (rec. 4244/2007); 18 octubre 2011 (rec. 2827/2010) o 20 noviembre 2012 (rec. 5165/2010).

STS 9 octubre 2000 (rec. 1438/1995).

STS 23 noviembre 1990 (rec. 71/1990).

SSTS 23 abril 1993 (rec. 5690/1991), 18 octubre 1999 (rec. 7256/1993) o 25 marzo 2003 (rec. 10089/1998).

SSTS 22 abril 1995 (s/rec.), 3 noviembre 1992 (rec. 5607/1990), 13 marzo y 1 julio 2001 (rec. 6752/1995), 20 y 26 febrero y 3 abril 2002 (rec. 7791/1996, 8933/1996 y 2075/1997) o 5 mayo 2003 (rec. 223/1993).

Entre estos motivos, SSTS 26 febrero 1988 (s/rec.); 24 febrero 1991 (rec. 272/1988); 24 septiembre 1991 (rec. 292/1988); 11 febrero y 18 marzo 1992 (rec. 7491/1990 y 4031/1990); 5 marzo 1994 (rec. 14248/1991); 4 octubre 1996 (rec. 1473/1993); 19 у 23 septiembre, 3 octubre y 9 diciembre 1997 (rec. 580/1994; 8315/1992, 7639/1994 у 3824/1994); 29 enero, 1 abril y 23 septiembre 1998 (rec. 2865/1995, 3563/1994 у 8315/1992); 10 febrero y 18 junio 1999 (rec. 3846/1993 y 5598/1993); 24 abril, 24 mayo y 25 octubre 2000 (rec. 5826/1994, 5528/1994 y 8584/1994); 17 enero 2001 (rec. 3837/1999); 1 abril 2004 (rec. 8644/1999); 5 abril 2005 (rec. 5420/2002) o 6 julio 2011 (rec. 451/2010). SSTS 21 junio 1994 (rec. 1077/1992), 11 noviembre 2002 (rec. 1651/1998), 14 enero y 1 marzo 2003 (rec. 7750/1998 y 10797/1998), 23 noviembre 2017 (rec. 2331/2015) o 20 febrero 2018 (rec. 3318/20159).

SSTS 28 julio 1988 (s/rec.), 12 marzo 1990 (s/rec.), 10 julio 1991 (rec. 1847/1990), 8 y 10 junio 1999 (rec. 4711/1993 y 6173/1993), 22 octubre 2001 (rec. 2018/1996), 9 octubre y 6 y 11 noviembre 2002 (rec. 8153/1997, 9014/1997 y 1651/1998), 11 marzo y 16 junio 2003 (s/rec. y 8565/1998) y 18 junio 2000 (rec. 3945/2005). 
sirva para la apertura de dos oficinas de farmacia ${ }^{91}$; de otro -y más común-, cuando tenga lugar la autorización firme de una nueva oficina de farmacia durante el periodo comprendido entre el día inicial (última farmacia abierta -no, por tanto, la autorizada pero nunca abierta ${ }^{92}$ ) y final de cómputo (fecha de solicitud de la farmacia por incremento de población), salvo cuando quepa apreciar un deliberado e improcedente retraso en la apertura de la farmacia intermedia autorizada ${ }^{93}$.

Por su parte, la población a considerar para una concreta autorización será la existente, con carácter general, al momento de la solicitud de apertura del procedimiento de autorización $^{94}$; únicamente de manera excepcional, la acreditada en el momento de efectuar la convocatoria al inicio del procedimiento ${ }^{95}$. Ello no empece, por supuesto, la posibilidad de valorar informes y documentos posteriores a dicha fecha ${ }^{96}$, pero sí vedará cualquier intento de llevar a cabo una delimitación distinta ${ }^{97}$.

$\mathbf{4}^{\mathbf{0}}$.- Conscientes de que los supuestos de mayor aproximación a la cifra exigida pueden encontrar solución a través del principio "pro apertura", la exclusión radical de fracciones en cualquier cómputo ${ }^{98}$.

$\mathbf{5}^{\mathbf{0}}$.- El papel que asumieron, y en muchos casos siguen asumiendo, los Colegios Profesionales. Así se contempla su quehacer dejando claro que "siempre actúan en la materia ejerciendo funciones o en su caso competencias que no son propias, sino de la Administración autonómica que se las ha encomendado. Por tanto, aunque no sería exacto declarar que actúan como órganos administrativos de aquella Administración, lo cierto es que ejercen competencias que de pleno derecho corresponde a aquella, por

91 Por todas, STS 11 noviembre 2002 (rec. 1651/1998); en igual sentido, SSTS 16 junio 2003 (rec. 8565/1998) o 7 octubre y 15 noviembre 2005 (s/rec. y 5351/2003).

92 STS 10 junio 1999 (rec. 6173/1993).

93 Con diferentes razones para hacer primar la última autorización, SSTS 11 noviembre 1993 (rec. 6700/1991), 24 noviembre 1995 (rec. 1874/1992), 16 junio 2003 (rec. 8565/1998), 7 octubre 2005 (rec. 2005/8471) o 28 octubre 2008 (rec. 458/2006).

94 SSTS 26 enero, 11 febrero y 15 junio 1994 (rec. 13386/1991, 1809/1993 y 1603/1992); 17 septiembre 1998 (rec. 8365/1992); 19 septiembre 2000 (rec. 8771/1994); 27 febrero y 9 julio 2001 (rec. 4441/1995 y 1334/1996); 14 enero 2003 (rec. 6623/1998); 14 noviembre 2006 (rec. 6314/2003); 17 noviembre 2008 (rec. 3307/2006); 10 marzo 2009 (rec. 9318/2004); 22 marzo 2011 (rec. 3698/2009) y 20 marzo 2015 (rec. 1690/2013). SSTS 16 septiembre y 10 noviembre 2009 (rec. 724/2007 y 4821/2007).

96 STS 20 noviembre 2001 (rec. 3378/1996).

97 STS 26 septiembre 2008 (rec. 6898/2005).

98 STS, Sala Especial del art. 61 LOPJ, 8 junio 1990 (rec. 161/1982) y SSTS 17 marzo y 31 mayo 1989 (ambas s/rec.); 2 febrero y 8 junio 1990 (s/rec. y 161/1989); 7 y 17 junio y 19 septiembre 1991 (rec. 347/1989, 1755/1989 y 2372/1989); 27 abril, 4 mayo, 28 julio y 16 noviembre 1992 (rec. 527/1990, 6754/1990, 7948/1990 y 11437/1990); 27 enero, 13 abril y 13 octubre 1993 (rec. 3645/1991, 6009/1990 y 403/1992); 14 y 22 junio y 18 y 24 noviembre 1994 (rec. 1579/1992, 1652/1992, 5133/1991 y 1673/1992); 13 septiembre 1995 (rec. 1874/1992); 16 y 25 enero y 20 abril 1996 (rec. 724/1993, 754/1993 y 161/1992); 5 mayo 1999 (rec. 4906/1993); 30 mayo 2000 (rec. 3266/1994); 22 octubre 2001 (rec. 2018/1996); 25 marzo 2002 (rec. 1414/1997) o 28 abril 2004 (rec. 104/2002). 
lo que ciertamente están actuando en concepto de lo que se denomina Administración impropia"99.

6.- La medición de la población a considerar ha planteado de continuo la cuestión de la vía apropiada a estos efectos, conscientes siempre de que se requiere un documento fiable para que no se lleve a cabo "a través de cálculos hipotéticos, sino que recaiga sobre datos objetivos constatados"100. De este modo, tras un período en que la polémica estuvo a la orden del día sobre cual había de ser el documento apropiado y cual la entidad certificante, obra jurisprudencia reiterada afirmando la preeminencia del padrón municipal frente a cualquier otro medio de prueba ${ }^{101}$.

Procederá sopesar, por tanto, "el vigente en fecha de solicitud, sin que se distinga ya entre población de hecho y de derecho, pues la única cifra que registra es la de residentes, habiendo desaparecido ya los conceptos de presentes, ausentes y transeúntes"102. De este modo, la certificación censal municipal ${ }^{103}$, o los módulos de población de las secciones censales que deben ser considerados en una zona farmacéutica ${ }^{104}$, quedan acreditados como referencia fundamental, a la cual pueden servir de complemento adecuado los certificados emitidos por el $\mathrm{INE}^{105}$, dada la presunción de corrección de que disfrutan ${ }^{106}$.

7.- Pero, sin duda, el mayor número de pleitos surge de la población no censada, bien de hecho, bien flotante, con particular relieve para aquellas personas con segunda residencia ${ }^{107}$. Desechando cualquier informe que tome en consideración a los futuros

99 Dejando claro cuanto se entrecomilla como literal de la STS 29 enero 2001 (rec. 4998/1995), entre más, SSTS 10 febrero 1993 (rec. 4526/1991) y 30 marzo 1994 (rec. 822/1992); aplicándolo a un supuesto de revocación de las funciones atribuidas, STS 19 abril 1989 (s/rec.).

100 STS 14 diciembre 1999 (rec. 1120/1994).

101 SSTS 7 marzo 1998 (rec. 2112/1996); 18 mayo 2005 (rec. 1871/2003); 18 mayo 2006 (s/rec.); 23 enero y 4 noviembre 2008 (rec. 8/2005 y 2112/2006); 10, 20 y 24 febrero, 2 junio, 16 septiembre, 21 octubre y 10 noviembre 2009 (rec. 8681/2004, 2420/2006, 174/2007, 4335/2006, 724/2007, 577/2008 y 4821/2007); 23 febrero 2010 (rec. 2518/2008); 12 abril, 5 junio, 17 julio y 6 noviembre 2012 (rec. 1740/2010, 978/2011, 2566/2010 y 4100/2011); 28 mayo 2013 (rec. 2631/2013); 3 noviembre 2014 (rec. 3562/2013) o 24 marzo 2015 (rec. 1690/2013).

102 SSTS 12 abril -dos - y 16 noviembre 2012 (rec. 1740/2010, 2089/2010 y 4100/2011).

103 SSTS 20 noviembre 2012 (rec. 1209/2012), 15 septiembre 2015 (rec. (3727/2013) o 22 junio 2016 (rec. 3837/2014).

104 SSTS 5 junio 2012 (rec. 6246/2010) y 15 septiembre 2015 (rec. 3727/2013).

105 STS 28 mayo 2013 (rec. 2631/2012). Para colegir que no han de ser computadas las viviendas vacías, SSTS 20 octubre 2009 (rec. 5723/2007), 22 marzo 2010 (rec. 5106/2007) y 6 julio 2015 (rec. 3494/2013).

106 SSTS 8 julio 2008 (rec. 5301/2005), 30 marzo 2010 (rec. 5439/2007), 28 mayo 2013 (rec. $2631 / 2012$ ) y 6 julio 2015 (rec. $3194 / 2013$ ).

107 Sirvan las reflexiones que al respecto, y en relación con el supuesto de segunda residencia, contienen las SSTS 9 mayo 2002 (rec. 4775/1996), 14 enero 2003 (rec. 7750/1998), 12 abril 2006 (s/rec.) o 29 abril 2019 (rec. 1886/2016). 
residentes $^{108}$, o la ponderación de viviendas en previsión de planeamiento o construcción $^{109}$, así como aquellas que se han acreditado que están vacías ${ }^{110}$, el Tribunal Supremo insiste en la pertinencia de tomar a este sector de población en consideración, llevando a su comprobación "por cualquier medio de prueba siempre que sea veraz, contundente, fiable y referido a la fecha de apertura de la farmacia"111.

Este criterio firmemente sostenido ha dado pie a la utilización de medios muy diversos para su cálculo ${ }^{112}$, "admitiéndose la prueba presuntiva o aproximativa, si bien debe fundarse en datos objetivos, seguros, comprobables o constatables"113.

Este es el supuesto que resulta de especial aplicación para el cálculo de la población de segunda vivienda o residencia ${ }^{114}$, como vía para llevar a "un índice de ocupación creíble"115. En esta operación se ha acudido (entre otros índices ${ }^{116}$ ) a la valoración del número de viviendas con un promedio de cuatro personas por vivienda ${ }^{117}$ a los contadores de agua y luz o el abono de residuos urbanos (sometidos a corrección cuando concurrieran con establecimientos comerciales o industriales) $)^{118}$, o a la consideración como residencias "de veraneo" para ponderar los días de

108 SSTS 3 mayo 1993 (rec. 5695/1991), 30 julio 1995 (rec. 5094/1993), 21 abril 1994 (rec. 4062/1993) o 5 junio 2001 (rec. 8059/1995). Con detalle, aun cuando ligeramente alejado en el tiempo, el ensayo de VIDA FERNÁNDEZ, J.: "Criterios para la autorización de apertura de farmacias: relevancia del padrón municipal, población flotante y población militar", Revista General de Derecho Administrativo (iustel), núm. 8, 2005 (recurso on line).

109 STS 10 junio 1990 (s/rec.).

110 SSTS 21 septiembre 2006 (rec. 3467/2004) y 11 junio 2007 (rec. 5413/2004).

111 Tal el literal que reza en las SSTS 31 marzo y 29 noviembre 2000 (rec. 3157/1994 y 2763/1995), 24 mayo 2001 (rec. 7853/1995) o 18 noviembre 2003 (rec. 6334/2000).

112 SST, Sala Especial art. 61 LOPJ, 24 febrero, 24 marzo y 19 junio 1990 (rec. 14/1989, s/rec. y 4/1990) y SSTS 6 octubre 1987 (s/rec.); 8 mayo 1990 (s/rec.); 3 junio 1991 (rec. 1697/1989); 3 noviembre 1992 (rec. 5607/1990); 24 febrero 1994 (rec. 6493/1992); 13 septiembre 1995 (rec. 1874/1992); 30 enero 1998 (rec. 3476/1992); 15 diciembre 1999 (rec. 39/1994); 29 noviembre 2000 (rec. 2763/1995); 6 noviembre 2002 (rec. 9014/1997); 22 enero, 4 febrero, 15 abril y 20 octubre 2003 (rec. 969/1998, 4182/1998, 580/1999 у 888/1999); 2 y 21 febrero, 4 mayo y 12 diciembre 2005 (rec. 5359/2000, 3501/2002, 7402/2002 y 3304/2003) o 11 abril 2006 (s/rec.).

113 Literal que sirve de aval a la aplicación de esta prueba de presunciones, por ejemplo, en las SST 5 abril 2005 (rec. 5420/2002), 10 marzo y 29 septiembre 2009 (rec. 9318/2004 y 5885/2007), 26 enero 2010 (rec. 5110/2008), 6 julio 2011 (rec. 451/2010) о 12 у 16 noviembre 2012 (rec. 6179/2010 y 4100/2011).

114 STS 9 mayo 2002 (rec. 4775/1996), 14 enero 2003 (rec. 7750/1998), 12 abril 2006 (s/rec.), 26 enero 2010 (rec. 5110/2008), 24 enero 2012 (rec. 1052/2009) o 29 abril 2019 (rec. 1886/2016).

115 SSTS 3 noviembre 2014 (rec. 3562/2013) y 16 diciembre 2015 -dos- (rec. 800/2014 y 813/2014).

116 Un elenco significativo en STS 3 noviembre 2014 (rec. 3562/2013).

117 SSTS 22 enero 2003 (rec. 969/1998), 18 octubre 2005 (s/rec.), 14 noviembre 2006 (rec. 6314/2003), 11 noviembre 2008 (rec. 4128/2006), 24 febrero 2009 (rec. 174/2007), 24 mayo 2011 (rec. 4190/2009) o 20 noviembre 2012 (rec. 1209/2012).

118 SSTS 14 febrero 2005 (rec. 3263/2002), 29 septiembre 2009 (rec. 5885/2007) o 24 noviembre 2011 (rec. 4190/2009). 
permanencia $^{119}$, intentando encontrar un promedio en el conjunto del año ${ }^{120}$ o considerando la proporción del periodo de estancia con el resto del año ${ }^{121}$. Tratando de objetivar este último parámetro se admite la previsión normativa que considera julio y agosto al 100\% de ocupación, el resto de los meses veraniegos entre el 40 y el $50 \%$, y asigna un número concreto de días a Navidad y Semana Santa ${ }^{122}$.

Al lado de las inclusiones mentadas (y de mayor interés al objeto de la sentencia comentada), cabrá recordar alguna de las exclusiones subjetivas que afectan al cómputo relacionado de la población flotante (la cual, por supuesto, pierde tal característica cuando los afectados estén censados ${ }^{123}$ ), pues obran pronunciamientos destinados a declarar que no procederá tomar en consideración a los "visitantes ocasionales"124 (como pudieran ser los que acuden en tal concepto a un recinto histórico-artístico ${ }^{125}$, a un puerto deportivo ${ }^{126}$ o un parque acuático ${ }^{127}$ ), los trabajadores en industrias situadas próximas al núcleo urbano (polígonos industriales cuando no se pernocta en núcleo o zona considerados ${ }^{128}$ ), los estudiantes y profesores que no permanecen en el ámbito objeto de consideración ${ }^{129}$, los clientes de centros comerciales $^{130}$, los turistas puramente puntuales ${ }^{131}$, los usuarios de ferrocarriles ${ }^{132}$ y aeropuertos $^{133}$, los asistentes a espectáculos deportivos ${ }^{134} \mathrm{o}$-en elenco abierto a variantes como la que en esta sentencia se analiza ${ }^{135}$ - cuantos no sean residentes en el supuesto de establecimientos militares

8.- En fin, y junto al módulo de población por obedecer al mismo interés de planificación, para garantizar así tanto la adecuada distribución como la accesibilidad, importa asegurar una correcta distancia de la nueva farmacia no solo respecto de otras

119 SSTS 24 septiembre 2001 (rec. 1980/1996) o 29 mayo 2011 (rec. 4190/2009).

120 STS 29 abril 1993 (rec. 7460/1991).

121 STS 22 diciembre 1993 (rec. 4957/1991).

122 STS 3 noviembre 2014 (rec. 3562/2013).

${ }^{123}$ SSTS 4 mayo y 12 diciembre 2005 (rec. 7402/2002 y 3304/2003) y 1 diciembre 2009 (rec. 12/2007).

124 STS 20 febrero 2002 (rec. 7791/1996).

125 STS, Sala Especial del art. 61 LOPJ, 6 junio 1990 (rec. 228/1989).

126 STS 27 mayo 1991 (s/rec.).

127 STS 2 noviembre 1995 (rec. 1584/1992).

128 SSTS 2 octubre 1990 (s/rec.), 22 diciembre 1993 (rec. 4957/1991), 21 febrero 1996 (rec. 126/1994) o 20 noviembre 2012 (rec. 5156/2010).

129 STS 2 octubre 1990 (s/rec.), 11 junio 2008 (3354/2005) y 20 noviembre 2012 (rec. $5165 / 2010)$.

130 SSTS 24 septiembre 2001 (rec. 1986/1996), 30 abril 2002 (rec. 3394/1997). En la doctrina, OSUNA GÓMEZ, F.: "Apertura de oficinas de farmacia: usuarios de grandes centros comerciales y cómputo de habitantes”, La Toga, núm. 98, 1998, págs. 21-25.

131 SSTS 3 octubre 1989 (s/rec.), 20 marzo 1991 (s/rec.), 12 noviembre 1992 (rec. 9665/1990) y 16 junio 1993 (rec. 8598/1991).

132 STS 30 abril 2002 (rec. 3394/1997).

133 STS 13 noviembre 2001 (rec. 3975/1996).

134 STS 24 septiembre 2001 (rec. 1980/1996).

135 Así las SSTS 19 junio y 8 julio 1996 (rec. 1484/1993 y 6126/1992), 22 enero y 28 abril 2003 (rec. 969/1998 y 1316/1999), 9 junio 2004 (rec. 7225/2001) o 15 abril 2009 (rec. 2131/2006). 
farmacias, sino también de hospitales y centros de salud o de cirugía ambulatoria de carácter público.

La razón de ser de esta última previsión (que se extiende no solo a centros sanitarios ya existentes, sino en proyecto ${ }^{136}$ ) radica en razones evidentes de competencia estableciendo una distancia capaz de impedir que la farmacia se convierta, por este dato, en centro de referencia para el paciente ${ }^{137}$, requiriendo de este modo una separación mínima que a veces provoca complejos litigios para su medición ${ }^{138}$.

Por cuanto hace a la distancia entre farmacias, como factor llamado a garantizar diferentes zonas de influencia o de prestación de servicio y asegurar la atención requerida por los ciudadanos - de ahí el interés profesional en la intervención al respecto de los Colegios Profesionales ${ }^{139}$-, su justificación siempre resultará necesaria ${ }^{140}$, aun cuando varios factores llevarán a matizar los metros que han de ser requeridos:

a) Si bien, con carácter general, la distancia mínima es exigible y exigida con todo el rigor ${ }^{141}$, no faltan ejemplo en las cuales se han valorado las circunstancias en presencia para admitir una cierta flexibilidad, pudiendo servir como ejemplo los ofrecidos en casos de municipios limítrofes ${ }^{142}$, continuos urbanos ${ }^{143}$ o entidades dispersas ${ }^{144}$. El motivo aducido se sitúa en la necesidad de ponderar otras circunstancias como, por ejemplo, que esa

136 STS 13 junio 1991 (rec. 2064/1989).

137 "Tiene como finalidad otorgar en este punto las debidas garantías respecto a la esfera de influencia o ámbito de prestación del servicio por unos y otros", STS 21 mayo 1992 (rec. 8163/1990).

138 No tomar en consideración un futuro paso subterráneo que podría hacer que la distancia fuera menor [STS 26 octubre 1983 ( $\mathrm{s} / \mathrm{rec}$.)], efectuar la medición hasta la puerta principal -y no otras de urgencias, minusválidos y otras emergencias-, y más exactamente hasta su centro [STS 13 junio 1991 (rec. 2064/1989)] o, por no seguir, la necesidad de computar el tramo que discurre entre los centros de la respectivas fachadas y el eje de las calzadas [STS 26 mayo 2006 (rec. 2602/2014)].

139 Exponiendo tal interés, entre más, SSTS 28 marzo 1983 (s/rec.), 24 febrero 1994 (rec. 6493/1992), 14 octubre 1998 (s/rec.) o 24 febrero 2009 (rec. 6264/2006).

140 La insistencia en este extremo aparece clara en pronunciamientos como los contenidos en SSTS 16 mayo 1984 (s/rec.), 19 noviembre 1989 (s/rec.), 17 septiembre 1990 (rec. 928/1989), 24 octubre y 14 noviembre 1991 (rec. 4009/1990 y 676/1989), 23 marzo 1992 (rec. 2005/1989), 23 febrero 1993 (rec. 4802/1991), 3 y 19 mayo y 18 octubre 1999 (rec. $5616 / 1995,4643 / 1993$ y 7256/1993), 24 mayo y 29 noviembre 2000 (rec. 5528/1994 y 2763/1995), 18 diciembre 2001 (rec. 4976/1996) o 31 enero y 22 marzo 2002 (rec. 6195/1996 y 2699/1997).

141 Para verlo, y entre los últimos, el contenido del pronunciamiento que recoge la STS 3 abril 2009 (rec. 1064/2007).

142 Confrontando pareceres en este punto, de un lado, SSTS 17 julio 1987 (s/rec.) y 16 octubre 1990 (s/rec.); de otro, STS 16 julio 1990 (s/rec.).

143 STS, Sala Especial art. 61 LOPJ, 8 junio 1990 (rec. 175/1989) o 14 mayo 2004 (rec. $3482 / 1999)$.

144 STS 22 diciembre 1993 (rec. 4957/1991). 
distancia conlleve especial incomodidad o riesgo para los clientes ${ }^{145}$; también en la valoración -en sentido contrario- de que el cumplimiento de la distancia "es uno de los requisitos exigidos, pero de esta exigencia no se puede sin más llegar (...) a que, siempre que concurra tal distancia, sea procedente la apertura de una oficina de farmacia, pues ni ello lo dice la norma que dispone el régimen sobre el establecimiento de oficinas de farmacia, ni lo ha dicho el Tribunal Supremo (...) [,el cual] siempre ha exigido algún elemento delimitador"146.

b) Algunos de los factores que obran como elementos delimitadores tienen que ver, por ejemplo, con la cuestión ya apuntada de supuestos de incompatibilidad absoluta entre traslados y apertura (pues el emplazamiento exigirá respetar la distancia hasta el local designado por el que tiene prioridad en el tiempo) ${ }^{147}$, o con la naturaleza sanitaria de los establecimientos y las restricciones históricas a su apertura en espacios comerciales, grandes superficies o polígonos industriales ${ }^{148}$, "con la excepción tal vez única de los aeropuertos"149.

c) En cuanto a la incidencia del factor analizado sobre la autorización hace, preciso será tener en cuenta la distinción jurisprudencial "entre, de un lado, la falta de obligación de designar desde un primer momento, el local concreto que ha de ocupar la farmacia y, de otro, la indudable necesidad de fijar un espacio territorial aproximado de futura ubicación de la misma cuando la razón que pueda justificar su apertura así lo exija"150.

En este sentido, "la doctrina que ha venido sentando esta Sala en torno al tema no ofrece dudas al respecto; si bien, en tesis general, no existe obligación de efectuar una concreta designación del local, o lugar concreto, en que se propone el solicitante establecer su farmacia en la primera fase del expediente de apertura, siempre que por las condiciones físicas del núcleo designado se

145 Recogiendo cuantiosos precedentes SSTS 24 octubre y 13 noviembre 2002 (rec. 2785/1998 y $855 / 1998)$.

146 STS 20 marzo 2002 (rec. 9393/2002).

147 Por su contundencia STS 9 julio 2004 (rec. 3439).

148 SSTS 18 septiembre 1991 (s/rec.), 28 enero y 18 noviembre 1992 (rec. 6110/1990 y 8228/1990) y 21 abril 1997 (rec. 1156/1991).

149 STS 23 enero 1992 (rec. 6335/1990).

150 Tenor literal que, con ligeras variaciones, se mantiene en la serie de pronunciamientos encabezados por la STS 13 noviembre 1990 (s/rec.), y que continúan las SSTS 22 noviembre 1991 (rec. 3135/1990), 22 abril 1992 (rec. 6001/1990), 10 mayo y 26 noviembre 1993 (rec. 5852/1991 y 4038/1991), 25 mayo y 2 julio 1994 (rec. 5193/1990 y 207/1992), 14 marzo 2001 (rec. 3875/1995) o 8 marzo 2002 (rec. 9044/1996). Sobre tan importante asunto, cabrá tomar en consideración la libertad del peticionario a la hora de organizar el procedimiento en una sola fase o en dos y, por tanto, con una designación genérica o $a b$ initio con las repercusiones que ello tiene no solo por el carácter vinculante de la petición específica (frente a la genérica), sino de la derivada de la prioridad, fundamentalmente en caso de concurrencia de peticiones con otras de traslado al mismo núcleo; al respecto, por extensión, GONZÁLEZ SALINAS, E.: "Designación de local para oficina de farmacia (Momento en que puede hacerse y prioridad en caso de concurrencia de solicitud de apertura con petición de traslado)", en AA.VV. (MARTÍN RETORTILLO BAQUER, L., Coord.): La protección jurídica del ciudadano (Procedimiento administrativo y garantía jurisdiccional), Vol. 3, Madrid (Civitas), 1993, págs. 2047-2060. 
haga imprescindible conocer esa ubicación para poder apreciar sustantividad con respecto al resto de la zona circundante, la falta de designación del lugar -siquiera en términos aproximados- en que se situaría el establecimiento es causa justificada de denegación de la petición. Y, precisamente, esa especial circunstancia concurre en todos aquellos supuestos en que la distancia haya de ser el elemento decisivo para poder apreciar la homogeneidad o sustantividad que ha de constituir la característica diferencial del núcleo, así como el único medio de apreciar si la totalidad de los residentes van a verse beneficiados, de una manera efectiva, por la existencia de la nueva oficina, o si, por el contrario, una parte notable de los mismos seguirán encontrándose más próximos a alguna de las farmacia ya existentes, haciendo decaer así la razón de apertura de la nueva oficina"151.

d) La importancia de una correcta ubicación a la hora de atender adecuadamente a la población para cuyo servicio se ha concedido ${ }^{152}$ influye en un criterio jurisprudencial a partir del cual, "cumplida la distancia mínima entre locales, no es la que separa a estos el factor determinante, sino la que han de recorrer los habitantes considerados para acceder al servicio farmacéutico que prestan las farmacias instaladas" $" 153$.

e) Pero, sin duda, la mayor parte de las cuestiones se refieren a cómo efectuar la medición, manteniéndose por vía jurisprudencial la pauta que en su momento concretó la regla $4^{\text {a }}$ de la Orden de 1 de agosto de 1959: "la medición de las distancias se hará siempre desde el camino vial más corto". Parámetro aquilatado con la prohibición de hacer deducciones de cualquier tipo y exigiendo que se efectúe por el eje de la calle o camino (art. 1.3.1 ${ }^{\circ}$ Decreto de 31 de mayo de 1947), y atendiendo a las variantes en función de la situación de las fachadas (regla $2^{\text {a }}$ Orden de 1 de agosto y 12 de diciembre de 1959), cruces de calles (regla $3^{\text {a }}$ de la Orden de 1 de agosto de 1959) o previsiones específicas para plazas y espacios abiertos (regla $2^{\mathrm{a}}$ de la Orden de 1 de agosto de 1959$)^{154}$.

Por tanto las variantes, son muy numerosas cuando los Tribunales entran a valorar las complejas pruebas periciales practicadas, para dejar ver que siempre habrá de

151 STS 14 enero 2003 (rec. 8786/1998). Para mostrar con claridad los dos supuestos referidos cabría remitir, por ejemplo, a las SSTS 19 septiembre 1991 (rec. 2209/1990) y 25 enero 2000 (rec. 638/1994).

152 SSTS 31 enero, 8 febrero y 25 marzo 2002 (rec. 6195/1996, 7601/1996 y 9046/1996) y 11 noviembre 2003 (rec. 4226/2000).

153 SSTS 10 mayo 1999 (rec. 4643/1993); 8 marzo, 22 julio, 24 octubre y 6 y 13 noviembre 2002 (rec. 2048/1997, 7825/1997, 2705/1998, 9014/1997 y 855/1998); 21 enero, 5, 6 y 13 mayo, 30 junio, 15 julio y 6 octubre 2003 (rec. 6912/1998, 223/1999, 11123/1999, 4747/1998, 3603/1999, 6999/1999 y 8810/1997); 26 enero, 1 marzo y 11 mayo 2004 (rec. $1278 / 2002,4662 / 2001$ y $3482 / 1999$ ) o 23 y 24 mayo 2005 (rec. 100/2004 y $2534 / 2003$ ).

154 Sobre esta evolución reglamentaria y la jurisprudencia primera a que dio lugar, GONZÁLEZ PÉREZ, J.: "La medición de distancia entre farmacias a efectos de otorgar la licencia de apertura", Revista de Administración Pública, núm. 32, 1960, págs. 141-150. 
asegurarse, a fin de llevar a la "distancia real"155, "el camino peatonal más corto, cómodo y accesible"156, trazado por el "eje de la acera y siguiendo los pasos peatonales, siempre por caminos viales de dominio público o uso público autorizado"157. Regla abierta a matices que, en el supuesto de zonas externas, lleva a ponderar la necesidad de medir "desde el límite o lindero del núcleo, no desde la finca existente"158; en el de pasajes, a diferenciar si su uso es permanente o no ${ }^{159}$ (incluso aunque fuera privado ${ }^{160}$ ); o en el de puertas y fachadas, a la necesidad de estar a su configuración en el caso concreto ${ }^{161}$, dado que obra un cúmulo de variantes de tanto interés como difícil comparación ${ }^{162}$.

Frente a los aspectos de doctrina jurisdiccional enunciados, el contenido de la sentencia analizada únicamente tendrá interés para un futuro respecto a la pertinencia o no de incluir en el cómputo de población, a efectos de calcular el número de habitantes para la autorización de nuevas farmacias, a quienes están alojados en residencias de personas mayores dotadas de farmacia, botiquín o depósito.

En tanto no se discute la pertinencia de autorizar las dos primeras, por aplicación del módulo de 2.800 habitantes, la cuestión se ciñe a la tercera farmacia derivada de la superación de aquella proporción y su posible autorización si concurriera una fracción superior a 2.000 habitantes en los términos contemplados en el art. 32.5 Ley 19/1991, de 25 de noviembre, de Ordenación y Atención Farmacéutica de la Comunidad de Madrid, y en el art. 3.1 del Decreto 115/1997, de 18 de septiembre.

El juzgador parte para su respuesta de un dato fáctico absolutamente definitivo: después de excluir a las personas que invoca la actora como alojados en las residencias de mayores (cifra no acreditada por la parte, pero tampoco discutida por la Comunidad Autónoma demandada), así como de aplicar a la cantidad resultante la proporción de una oficina de farmacia por cada 2.800 habitantes, el resto de la población es superior a 2.000 habitantes, motivo por el cual la Dirección General de Inspección y Ordenación quedaría legitimada para autorizar esa tercera farmacia; descartando, por la fuerza de los datos, la disconformidad a Derecho de las resoluciones impugnadas.

Dos razones más se añaden para llevar a igual conclusión: en primer lugar, el art. 32 de la Ley "aplica el módulo poblacional teniendo en cuenta solo el número de oficinas de farmacia existentes en la zona farmacéutica en cuestión, por lo que ninguna relevancia tendría, en realidad -y al margen de no ser necesario acudir a ello en esta

155 STS 10 mayo 1999 (rec. 4643/1993).

156 Y ello aunque suponga que es preciso "circunvalar plaza y no haya paso de peatones", SSTS 10 noviembre 2008 (rec. 4105/2006) y 20 septiembre 2011 (rec. 1171/2010).

157 "No por zona ajardinada y uso peatonal privados", STS 17 febrero 2009 (rec. 77/2007).

158 STS 29 noviembre 2006 (rec. 4145/2004).

159 STS 20 noviembre 1992 (rec. 2885/1991).

160 La discrepancia a la hora de considerar los pasajes en función de si su acceso y tránsito es factible en SSTS 28 septiembre 1996 (rec. 862/1993) y 12 julio 2000 (rec. 7970).

161 Por ejemplo, STS 14 octubre 1998 (rec. 8746/1992).

162 Sirvan así, entre muchos más, los interesantes supuestos dedicados a esta cuestión que contemplan las SSTS 31 octubre 1995 (rec. 1921/1992) o 30 abril, 4 y 21 octubre y 9 diciembre 1996 (rec. 7195/1992, 1473/1993, 4378/1991 y 472/1993). 
ocasión-, la existencia de farmacias hospitalarias, botiquines o depósito de medicamentos existentes en residencias de personas mayores"; en segundo término, ya existía un pronunciamiento previo de la Sala ${ }^{163}$, confirmado por el Tribunal Supremo ${ }^{164}$, interpretando los aspectos sustanciales que inciden en el debate.

En este último sentido, aquella sentencia ya puso en claro que:

- "La facultad de autorizar y establecer una nueva oficina de farmacia por fracción superior a 2.000 habitantes en una determinada zona farmacéutica tiene lugar cuando se supera la proporción indicada, no los habitantes indicados, esto es, no cuando se superan los primeros 2.800 habitantes computados de la zona farmacéutica, o los 2.800 habitantes computados que exceden de los que corresponden a las oficinas de farmacias ya existentes en una determinada zona farmacéutica"165.

- Proporción es "la correspondencia debida entre cosas relacionadas entre sí; de forma que superada la correspondencia prevista en los indicados preceptos entre una oficina de farmacia y 2.800 habitantes censados en la zona farmacéutica, si este resto es una fracción superior a 2.000 habitantes e inferior a 2.800, la Administración sanitaria 'podrá' autorizar una nueva oficina de farmacia".

- "Obviamente, si este resto o fracción alcanzara el módulo de los 2.800 habitantes, la administración sanitaria 'deberá' autorizar la oficina de farmacia que corresponde a éste módulo, pues del artículo 2.3 LRSOF se desprende que todas las oficinas de farmacia que se puedan crear en una determinada zona farmacéutica en función de la proporción indicada de una farmacia por cada 2.800 habitantes son de creación obligatoria, y ello por contraposición al carácter potestativo que tiene la autorización de la oficina de farmacia cuando el resto de población que resulte de aplicar dicha proporción sea una fracción -del módulo de 2.800 habitantes- que exceda de 2.000 habitantes y, por supuesto, no alcance los 2.800, pues si alcanzase esta cifra de población, tal resto constituiría no una fracción del módulo, sino el módulo mismo, que determina la necesidad de aplicar la proporción contemplada en el precepto $\mathrm{y}$, en consecuencia, la obligación de autorizar otra oficina de farmacia más".

163 STSJ Madrid 2 junio 2010 (rec. 278/2009).

164 STS 17 abril 2012 (rec. 4683/2016).

165 En este punto, de interés sobre la evolución de esta jurisprudencia, VIDAL CASERO, M. C.: "La apertura de oficinas de farmacia en núcleos de población de 2000 habitantes: la interpretación jurisprudencial", Revista General de Derecho, núm. 616-617, 1996, págs. 201-220; su origen en GONZÁLEZ PÉREZ, J.: "La apertura de farmacias para que queden mejor atendidos los núcleos de población de dos mil habitantes", Revista de Administración Pública, núm. 44, 1964, págs. 283-300. La modificación definitiva hasta la actualidad en RAZQUÍN LIZARRAGA, J. A.: "La apertura de oficinas de farmacia por núcleo de población de 2000 habitantes: reciente giro jurisprudencial (A propósito de las SSTS de 26 septiembre y 4 octubre 1996)", Actualidad Jurídica Aranzadi, núm. 298, 1997, $\mathrm{BIB} \backslash 1997 \backslash 158$. 


\section{Bibliografía}

AGRAZ PÉREZ-ENRÍQUEZ, L. y NAVARRO FUENTES, M.: "Apertura de oficinas de farmacia en la Comunidad de Madrid", Acofar, núm. 389, 2000.

BAETEN, R. y PALM, W.: "The compatibility of healthcare capacity planning polices with EU internal market rules", en AA.VV. (VAN DE GRODEN, J. et alii, Eds.): Healthcare and EU Law. Legal issues of services of general interest, La Haya (TMC Asser Press), 2011.

BAETEN, R.: "Was the exclusion of healthcare from the Services Directive a pyrrhic victory? A proportionality test on regulation of health professions", OSE Paper Series, núm. 18, 2017.

BAEYENS, A. y GOFFIN, T.: "Selected legislation and jurisprudence. European Court of Justice", European Journal of Health Law, Vol. 17, 2010.

BARBARISI, I. et alii.: "A spatial analysis to evaluate the impact of deregulation policies in the pharmacy sector: Evidence from the case of Navarre", Health Policy, Vol. 123, núm. 11, 2019, págs.1108-1115.

BASSOLS COMA, M.: "Competencias transferidas a las Comunidades Autónomas en materia de Derecho Sanitario y Farmacéutico", en AA.VV.: Derecho Farmacéutico de las Comunidades Autónomas, Madrid (Consejo General de Colegios Oficiales de Farmacéuticos), 1987.

BEL PRIETO, E. y SUÑÉ ARBUSSÁ, J.M.: "Estudio crítico de la Ley de Ordenación Farmaceuta de Cataluña (I). La oficina de farmacia ( $1^{\mathrm{a}}$ y $2^{\mathrm{a}}$ parte)", Offarm, Vol. 12, núms. 1 y 2, 1993.

BROOKS, E.: "Crossing borders: A critical review of the role of the European Court of Justice in EU health policy", Health Policy, Vol. 105, núm. 1, 2012, págs. 33-37.

CABEZAS LÓPEZ, M. D.; PIQUERAS GARCÍA, A. y GÓMEZ BETETA, J. E.: "El modelo mediterráneo de farmacia y la libertad de establecimiento en la Unión Europea", Ars Pharmaceutica, Vol. 51, núm. 3, 2010.

CARRASCOSA SALMORAL, A: "Apertura de oficinas de farmacia en Andalucía", La Toga, núm. 138, 2002.

CARROBLES GARCÍA, J.: Manual práctico de apertura y gestión de farmacias en Castilla-La Mancha, Cuenca (Alfonsípolis), 2000.

CERVERA SOTO, S.: "El modelo de atención farmacéutica en la legislación de Navarra", Derecho y Salud, Vol. 9, núm. 1, 2001, págs. 1-8.

CUETO PÉREZ, M.: Ordenación farmacéutica: regulación estatal y autonómica, Madrid (Marcial Pons), 1998.

CUETO PÉREZ, M.: "Ordenación farmacéutica: competencias y funciones de las Comunidades Autónomas", Revista Española de Administración Local y Autonómica, núm. 276, 1998. 
EZQUERRA HUERVA, A.: "El modelo español de ordenación farmacéutica en el contexto comunitario europeo de libertad de establecimiento", Derecho y Salud, Vol. 16, 2008.

EZQUERRA HUERVA, A.: "Acerca del blindaje comunitario de la reserva de la propiedad de las oficinas de farmacia a favor de los farmacéuticos. Consideraciones al hilo de las sentencias del Tribunal de Justicia de las Comunidades Europeas de 19 de mayo de 2009 (asuntos acumulados C-171/07 y C-172/07, y asunto C-531/06)", Revista de Administración Pública, núm. 180, 2009.

FERNÁNDEZ GONZÁLEZ, F. J.: "La ordenación y planificación de las oficinas de farmacia en el Estado de las Autonomías", Revista Española de Administración Local y Autonómica, núm. 276, 1998.

GAGO CABEZUDO, M. J.: La farmacia en Castilla La-Mancha. Incidencia normativa y social, Tesis Doctoral, Universidad Complutense de Madrid, 2002, en https://dialnet.unirioja.es/servlet/tesis? $\operatorname{codigo}=165953$.

GARATTINI, L.; VAN DE VOOREN, K. y CURICO, A.: "Will the reform of community pharmacies in Italy be of benefit to patients or the Italian National Service?", Drugs \& Therapy Perspectives, Vol. 28, núm. 11, 2012, págs. 23-26.

GARCÍA DE PABLOS, J. F.: "Apertura de farmacias y la normativa comunitaria", Actualidad Jurídica Aranzadi, núm. 801, 2010, BIB\2010\1389.

GARCÍA DE PABLOS, J. F.: "Apertura de farmacias en España y libertad de establecimiento", Aranzadi Doctrinal, núm. 10, 2011, BIB\2010\3044.

GARCÍA ESCRIBANO MARTÍNEZ, M. S.: El derecho de establecimiento de las oficinas de farmacia en la Unión Europea, Tesis Doctoral, Universidad Complutense, 1997, en dialnet.unirioja.es/servlet/tesis? codigo $=173761$.

GARCÍA MONTOYA, L.: "Límites nacionales a la apertura de nueva farmacia vs. libertad de establecimiento del art. 49 TFUE", CESCO. Notas jurisprudenciales, 7 de abril de 2014.

GOMES, M. et alii: "Dinâmica e concorrência regulada do mercado das farmacias em Portugal", Revista Portuguesa de Farmacoterapia, Vol. 9, núm. 2, 2017, págs. 213-221.

GONZÁLEZ ALONSO, I. y BARA BANDRÉS, M. P.: "Modelos de farmacia en la Unión Europea. Análisis comparativo", Farmacia Profesional, Vol. 22, núm. 8, 2008, págs. 10-15.

GONZÁLEZ ALONSO, I. y BARA BANDRÉS, M. P.: "Grandes cadenas de farmacias presentes en el entorno europeo", Farmacéuticos Comunitarios, Vol. 1, núm. 2, 2009, págs. 59-63.

GONZÁLEZ FERNÁNDEZ, F. J.: "Las limitaciones a la libertad de apertura de nuevas oficinas de farmacia tras la reforma de la ordenación farmacéutica", en AA.VV. (SOSA WAGNER, F., Coord.): El Derecho Administrativo en el umbral del siglo XXI. Homenaje al Profesor Dr. D. Ramón Martín Mateo, Valencia (Tirant lo Blanch), 2000. 
GONZÁLEZ PÉREZ, J.: "La medición de distancia entre farmacias a efectos de otorgar la licencia de apertura", Revista de Administración Pública, núm. 32, 1960, págs. 141-150.

GONZÁLEZ PÉREZ, J.: "La apertura de farmacias para que queden mejor atendidos los núcleos de población de dos mil habitantes", Revista de Administración Pública, núm. 44, 1964, págs. 283-300.

GONZÁLEZ PÉREZ, J.: Nueva ordenación de las oficinas de farmacia, Madrid (BOE), 1978.

GONZÁLEZ PÉREZ, J.: "La constitucionalidad de la legislación sobre establecimiento de farmacias (Sentencia de 10 de mayo de 1983)", Revista Española de Derecho Administrativo, núm. 39, 1983.

GONZÁLEZ PÉREZ, J. y GONZÁLEZ SALINAS, E.: La reforma de la ordenación farmacéutica (Decreto-Ley 11/1996, y legislación de las Comunidades Autónomas), Madrid (Civitas), 1996.

GONZÁLEZ SALINAS, E.: "Designación de local para oficina de farmacia (Momento en que puede hacerse y prioridad en caso de concurrencia de solicitud de apertura con petición de traslado)", en AA.VV. (MARTÍN RETORTILLO BAQUER, L., Coord.): La protección jurídica del ciudadano (Procedimiento administrativo y garantía jurisdiccional), Vol. 3, Madrid (Civitas), 1993, págs. 2047-2060.

GRANDA, E.: “Modelos de farmacia: comparativa europea. ¿Somos diferentes?”, Farmacia Profesional, Vol. 25, núm. 2, 2011.

GRANDA, E.: "Ordenación farmacéutica y economía de las farmacias: conclusión y recomendaciones", Farmacia Profesional, Vol. 31, núm. 3, 2017.

HANCHER, L.: "The EU pharmaceuticals market: parameters and pathways", en AA.VV. (MOSSIALOS, E. et alii, Eds.): Health systems governance in Europe: The role of European Union Law and Policy, Cambridge (Cambridge University Press), 2010, págs. 635-682.

HERNÁNDEZ SAN JUAN, I.: "La autorización administrativa de apertura de oficinas de farmacia", en AA.VV. (PAREJO ALFONSO, L. Dir.): Autorizaciones y licencias, hoy. Un análisis sectorial tras la Directiva de Servicios, Valencia (Tirant lo Blanch), 2013.

KÄLVEMARKY SPORRONG, S. y NORDÉN-HÄGG, A.: “Trends in pharmacy staff's perception of patient safety in Swedish community pharmacies after reregulation of conditions", Phamacy Practices, Vol. 12, núm. 4, 2014, págs. 1-5.

LARRUMBE SANMARTÍN, F.: "Liberalización de la apertura de oficinas de farmacia: constitucionalidad de la Ley Foral Navarra", Actualidad Jurídica Aranzadi, núm. 623, 2004, BIB \2004\382.

LLUCH, M. y KANAVOS, P.: "Impact of regulation of community pharmacies on efficiency, access and equity. Evidence from UK and Spain", Health Policy, Vol. 110, núm. 2-3, 2010, págs. 245-254. 
LÓPEZ SANTIAGO, A.: "Apertura de oficinas de farmacia. Análisis de situación”, Farmacia Profesional, Vol. 15, núm. 9, 2001.

MALENOVSKY, J.: "Apertura de nuevas farmacias (TJ Sala Cuarta, S 13 febrero 2014)", La Ley Unión Europea, núm. 13, 2014.

MARTÍN BAREA, M. P. y ESPINOSA RAMOS, E.: "Ley de Ordenación Farmacéutica de Cataluña", Offarm, Vol. 11 núm. 6, 1996.

MARTÍN MATEO, R.: "Ordenación farmacéutica, medicamentos y productos sanitarios", en AA.VV.: Jornadas Técnicas de Sanidad y Seguridad Social en el Estado de las Autonomías, Barcelona (Instituto d'Estudis de la Salud/Generalitat de Catalunya), 1984.

MARTÍN MATEO, R.: "La ordenación de las oficinas de farmacia", Derecho y Salud, Vol. 3, núm. 2, 1995.

MARTÍN RETORTILLO, S.: "Acción administrativa sanitaria: la autorización para la apertura de farmacias", Revista de Administración Pública, núm. 24, 1957.

MESTRE DELGADO, J. F.: "La competencia normativa en materia de ordenación farmacéutica", Derecho y Salud, Vol. 5, núm. 2, 1997.

MORALES ARIZA, S. M.: Ordenación farmacéutica española: situación actual y perspectivas de futuro, Tesis Doctoral, Universidad de Valencia, 2015, en https://core.ac.uk/reader/71056520.

MOSSIALOS, E. y LEAR, J.: "Balancing economic freedom against social policy principles: EC Competition Law and national health systems", Health Policy, Vol. 106, núm. 2, 2012, págs. 127-137.

MUELAS TIRADO, J.: Régimen jurídico de apertura y actividad de las oficinas de farmacia, Tesis Doctoral, Universidad de Valencia, 2002, en dialnet.unirioja.es/servlet/tesis? codigo $=21867$.

MUÑOZ PEREA PIÑAR, I.: Diferencias en las normativas autonómicas para la apertura de oficina de farmacia, Tesis Doctoral, Universidad Alfonso X el Sabio, 2017, en https://dialnet.unirioja.es/servlet/tesis?codigo=219567.

NICOLÁS ORTÍZ, C.: "Defensor del Pueblo: 'pro apertura' de farmacias", Farmacia Profesional, Vol. 8, núm. 9, 1994, págs. 5-9.

NIETO, A.: "La Ley alemana de Farmacia de 28 de agosto de 1960", Revista de Administración Pública, núm. 35, 1961.

ORDÓÑEZ SOLÍS, D.: "La regulación española de las oficinas de farmacias en el contexto del mercado único a la luz de la jurisprudencia europea", Gaceta Jurídica de la Unión Europea y de la Competencia, núm. 10, 2009.

OSUNA GÓMEZ, F.: "Apertura de oficinas de farmacia: usuarios de grandes centros comerciales y cómputo de habitantes", La Toga, núm. 98, 1998, págs. 21-25.

PÉREZ GÁLVEZ, J. F.: Farmacia y patrimonio: un estudio de la relación jurídica de servicio farmacéutico, Andújar (Ibarra de Arce), 1999. 
PÉREZ GÁLVEZ, J. F.: "Libertad de establecimiento de farmacias en la Unión Europea", Revista de Derecho de la Pontificia Universidad Católica de Valparaíso, Vol. XXXV, 2010, $2^{\circ}$ semestre.

POU VIVER, T.: "Nuevo concepto jurisprudencial de núcleo a efectos de apertura de farmacia”, Revista Española de Derecho Administrativo, núm. 96, 1997, págs. 603-608.

RAZQUÍN LIZARRAGA, J. A.: "La apertura de oficinas de farmacia: el Real Decreto-Ley 11/1996, de 17 de junio”, Actualidad Jurídica Aranzadi, núm. 262, 1996.

RAZQUÍN LIZARRAGA, J. A.: "La apertura de oficinas de farmacia por núcleo de población de 2000 habitantes: reciente giro jurisprudencial (A propósito de las SSTS de 26 septiembre y 4 octubre 1996)", Actualidad Jurídica Aranzadi, núm. 298, 1997, BIB \1997\158.

RAZQUIN LIZARRAGA, J. A.: "La reserva de la propiedad y la titularidad de las oficinas de farmacia a los farmacéuticos no es contraria al Derecho Comunitario Europeo", Actualidad Jurídica Aranzadi, núm. 777, 2009, BIB \777\2009.

RAZQUÍN LIZARRAGA, J. A.: "La ordenación territorial de las oficinas de farmacia en España y el Derecho de la Unión Europea (Sentencia del Tribunal de Justicia de 1 de junio de 2010, C-570/07 y C-571/07, Blanco Pérez y Chao C.)", Aranzadi Unión Europea, núm. 7, $2010, \mathrm{BIB} \backslash 2010 \backslash 7412$.

RIVERO YSERN, J. L.: Libertad de establecimiento de oficinas de farmacia, Madrid (Trivium) 1992.

SERRATO MARTÍNEZ, L.: Régimen jurídico-administrativo del medicamento, Tesis Doctoral, Universitat de Lleida, 2014, en https://repositori.udl.cat/handle/ 10459.1/64107.

SHARPF, F. W.: "The European social model", Journal of Common Market Studies, Vol. 40, núm. 4, 2002.

SUÑÉ ARBUSSA, J.M. y BEL PRIETO, E: "La ordenación farmacéutica en las Comunidades Autónomas. Determinación del número de farmacias (I). Módulos poblacionales y distancias”, Offarm, Vol. 19, núm. 1, 2000, págs. 106-113.

SUÑÉ ARBUSSA, J.M. y BEL PRIETO, E: "La ordenación farmacéutica en las Comunidades Autónomas. Determinación del número de farmacias (II). Estudio comparativo", Offarm, Vol. 19, núm. 2, 2000, págs. 124-134.

SUÑÉ ARBUSSA, J.M. y BEL PRIETO, E: "La ordenación farmacéutica en las Comunidades Autónomas (III). Medición de distancias", Offarm, Vol. 19, núm. 5, 2000, págs. 152-164.

TAPIA HERMIDA, A.: "Las limitaciones a la apertura de nuevas farmacias", Revista de Trabajo y Seguridad Social (CEF), núm. 332, 2010.

TRIBUNAL DE DEFENSA DE LA COMPETENCIA: La competencia en España: balance y nuevas perspectivas, Madrid (Tribunal de la Competencia), 1995, pág. 229-271. 
VIDA FERNÁNDEZ, J.: "Criterios para la autorización de apertura de farmacias: relevancia del padrón municipal, población flotante y población militar", Revista General de Derecho Administrativo (iustel), núm. 8, 2005 (recurso on line).

VIDAL CASERO, M. C.: "El desarrollo evolutivo de la reglamentación sobre garantías en los procedimientos de apertura de nuevas oficinas de farmacia", Revista General Informática de Derecho, núm. 1, 200, (recurso on line).

VIDAL CASERO, M. C.: "La apertura de oficinas de farmacia en núcleos de población de 2000 habitantes: la interpretación jurisprudencial", Revista General de Derecho, núm. 616-617, 1996, págs. 201-220.

VIDAL CASERO, M. C.: "La apertura de oficinas de farmacia y la aplicabilidad del Real Decreto 909/1978, artículo 3.1”, La Ley, T. 2, 1996, págs. 1604-1607.

VIDAL CASERO, M. M.: "La apertura de oficinas de farmacia en el País Vasco", $E l$ farmacéutico: profesión y cultura, núm. 210, 1998, págs. 74-79.

VIDAL CASERO, M. M.: "La apertura de oficinas de farmacia en el País Vasco", El farmacéutico: profesión y cultura, núm. 225, 1999, págs. 104-110.

VILLABA PÉREZ, F. L.: La profesión farmacéutica, Madrid (Marcial Pons), 1996.

VILLALBA PÉREZ, F. L.: "Disposición adicional sexta. Oficinas de farmacia", en AA.VV. (GARCÍA PÉREZ, R. y ALBIEZ DOHRMANN, K. J., Dirs.): Comentarios a la Ley de Sociedades Profesionales. Régimen Fiscal y Corporativo, Cizur Menor (Aranzadi/Thomson), 2007.

VILLALBA PÉREZ, F. L.: "La necesaria previsibilidad y estabilidad del ejercicio profesional del farmacéutico de oficina de farmacia", Revista Española de Derecho Administrativo, núm. 152, 2011.

VILLALBA PÉREZ, F.: "La protección de la salud como factor determinante de la libertad de establecimiento de la oficina de farmacia española y el Derecho Comunitario", Noticias de la Unión Europea, núm. 312, 2011, págs. 51-68.

VOGLER, S.; HABIMANA, K. y ARTS, D.: "Does deregulation in community pharmacy impact accessibility of medicines, quality of pharmacy services and costs? Evidence from nine European countries", Health Policy, Vol. 117, núm. 3, 2014, págs. 311-327.

WAGNER, A. et alii: "Equity in the distribution of community pharmacies in England: impact of regulatory reform", Journal of Health Services Research \& Policy, Vol. 14, núm. 4, 2009, págs. 243-248.

WASSERFALLEN, F.: "The judiciary as legislator? How the European Court of Justice shapes policy-making in European Union”, European Public Police, Vol. 17, núm. 8, 2010, págs. 1128-1146.

ZÚÑIGA LÓPEZ, J. M.: "La apertura de las oficinas de farmacia al amparo de los arts. 3.1 B) del Real Decreto 909/1978, de 14 de abril, y 3.1 de la Orden Ministerial de 21 de noviembre de 1979”, La Ley, T. I, 1997, págs. 1819-1822. 